\title{
Numerical Investigation on the Effects of Circuit Parameters on the Plastic Deformation of Fastener Holes in Thin Aluminum Alloy via Electromagnetic Expansion Process
}

\author{
Xiaofei Xu \\ Xiangtan University \\ Huihui Geng \\ Huazhong University of Science and Technology \\ Qingshan Cao \\ Huazhong University of Science and Technology \\ Quanliang Cao \\ Huazhong University of Science and Technology \\ Liang Li \\ Huazhong University of Science and Technology \\ Xiaoping Ouyang ( $\Delta$ oyxp2003@aliyun.com ) \\ Xiangtan University
}

\section{Research Article}

Keywords: Electromagnetic strengthening, Hole expansion, Dual-coil system, Plastic deformation

Posted Date: March 22nd, 2021

DOl: https://doi.org/10.21203/rs.3.rs-330370/v1

License: (c) (i) This work is licensed under a Creative Commons Attribution 4.0 International License. Read Full License

Version of Record: A version of this preprint was published at The International Journal of Advanced Manufacturing Technology on August 2nd, 2021. See the published version at https://doi.org/10.1007/s00170-021-07793-x. 


\section{Numerical investigation on the effects of circuit parameters on the plastic deformation of fastener holes in thin aluminum alloy via electromagnetic expansion process}

Xiaofei $\mathrm{Xu}^{1}$, Huihui Geng ${ }^{2,3}$, Qingshan $\mathrm{Cao}^{2,3}$, Quanliang $\mathrm{Cao}^{2,3}$, Liang $\mathrm{Li}^{2,3 *}$ and Xiaoping Ouyang ${ }^{1 *}$

${ }^{1}$ School of Materials Science and Engineering, Xiangtan University, Xiangtan, 411105, Hunan, China

${ }^{2}$ Wuhan National High Magnetic Field Center, Huazhong University of Science and Technology, Wuhan, 430074, China

${ }^{3}$ State Key Laboratory of Advanced Electromagnetic Engineering and Technology, Huazhong University of Science and Technology, Wuhan, 430074, China

*Corresponding author: liangli44@mail.hust.edu.cn (L. Li); oyxp2003@aliyun.com (X. Ouyang)

Abstract: The size of plastic deformation zone during fastener hole strengthening is a critical indicator of the strengthening effect. In this study, a considerable plastic deformation zone in $1.5 \mathrm{~mm}$ aluminum alloy plate with a hole was produced via electromagnetic strengthening. The finite element analysis results showed that the electromagnetic strengthening process could achieve high compressive hoop residual stress around the fastener hole in thin plate without serious axial deformation compared with conventional cold hole expansion process. The simulation results were experimentally validated by the grid method. Furthermore, for the same discharge energy, the size of plastic deformation zone varies with the discharge capacitance, and there was an optimal combination of the discharge capacitance and discharge voltage. What's more, even the plastic deformation zone was the same at the maxed load, different unloading process during the electromagnetic hole expansion process also had 
a great influence on the strengthening effect.

Keywords: Electromagnetic strengthening; Hole expansion; Dual-coil system; Plastic deformation

\section{Introduction}

For the purpose of jointing the fasteners in aircrafts, automobiles etc., it's unavoidably to drill holes in these engineering structures and components. However, cracks during cycling loads are much more preferred to initiate around holes owing to the severe stress concentration issue, which would significantly reduce the fatigue life of the fasteners [1]. To improve the service life and reliability of the devices, it's important to extend the fatigue life of these fastener holes. Conventional hole strengthening methods, named cold working, such as direct cold expansion [2], split sleeve cold expansion [3-6] and shot peening [7], have already been developed. The principle of these methods is to push the hole wall radially outward, then the elastic/plastic deformation is occurred. When the external load is removed, the plastic deformation zone(PDZ) would be compressed by the spring-back of the surrounding elastic area, thus the compressive residual stress is produced, and the larger PDZ, the stronger compressive residual stress [8]. This compressive residual stress would reduce the service tension stress, which could suppress the initiation of the crack and then extend the fatigue life [9].

The area of the PDZ is an important indicator of the strengthening effect. The widely used hole strengthening methods produced more considerable PDZ in thick Al fasteners holes than in thin Al plates. To increase the fatigue life of the fastener with 
holes, the most effective way is to increase the degree of interference fit to a certain extent, this would introduce a larger size of PDZ [10,11], a higher compressive residual stress $[1,12,13]$ and a longer fatigue life [14]. However, Sanford and Link [11] pointed that, when the degree of interference fit is higher than 5\%, the out-of-plane deformation, ascribed to the pulling of the hardened mandrel, would hinder the further expansion of the PDZ in the radial direction. As for thin fasteners with holes, Ofsthum [9] pointed that the cold working method would reduce the fatigue life of $1.422 \mathrm{~mm}$-thick Al sheets. He found that, with the pulling through of the mandrel, a significant volcano was formed around the hole in the thin sheet, and he claimed that was a hole extrusion rather than hole expansion. Amjad et al. [8] and Poolsuk and Sharpe [10] also found that, compared with the PDZ in thin fasteners, they found a more axisymmetric and larger PDZ was formed in the thick fasteners. These investigations demonstrate that, the conventional hole strengthening methods are not effective in introducing PDZ in thin sheets, and would even destroy the thin fasteners. Moreover, the mainly limiting factors in strengthening thin sheets with holes was the out of plane deformation during the strengthening process, ascribing to the axial movement of the tool in direct contact with the hole wall. Therefore, a new method which could overcome the above-mentioned obstacles is in urgent demand for strengthening thin fasteners.

Recently, a new method, named electromagnetic cold-expansion (EMCE), has been developed to strengthen the holes in fasteners [15]. The EMCE process was a noncontact method, and the force needed to yield the Al sheets was the Lorentz force induced around the hole. Furthermore, there was no pulling or pushing of the mandrel 
along the axial direction. These inherent features make EMCE particularly suitable for thin fasteners with holes. It has been proved that the effect of electromagnetic process could be influenced by the parameters of the circuits [16-21]. However, few studies have been reported about the influenced of circuits on the PDZ of thin specimens via EMCE process.

In this study, a coupled finite element method (FEM) was used to investigate the influence of circuit parameters on the plastic deformation zone in $1.5 \mathrm{~mm}$-thick $2 \mathrm{~A} 12$ T4 plate with a concentric hole via EMCE. To this end, the elastic/plastic behavior of the 2A12-T4 Al alloy under electromagnetic process was modeled via COMSOL Multiphysics, and the simulation results of the final radial strain were verified by grid method. In addition, the effects of the pulse width of the pulsed current on the size of PDZs, as well as the influence of the radially inward force during the unloading process on the residual stress, were investigated. Finally, the fatigue life improvement of rectangle fasteners with hole via EMCE was presented. In the following sections, the principle of the developed EMCE system, the numerical models, the numerical and experimental analysis are introduced in detail.

\section{Basic principle of cold expansion via electromagnetic method}

The basic principle of EMCE is similar to that of the widely-studied electromagnetic forming, that is the use of pulsed Lorentz forces to achieve plastic deformation of workpiece [18, 22-25]. During the strengthening process, an induced eddy current in the workpiece and a pulsed magnetic field in space are generated as the pulsed current flows through the coils which is placed near a workpiece. Thus, a strong 
pulsed Lorentz force is formed in the workpiece, and its density is

$$
f_{L}=J \times B
$$

in which $\boldsymbol{J}$ and $\boldsymbol{B}$ are eddy current density and magnetic flux density in the workpiece, respectively.

Generally, in the axisymmetric case, the eddy current $\boldsymbol{J}$ has only one component $J_{p h i}$ along the circumferential direction, and the magnetic flux density has two components $B_{r}$ and $B_{z}$. Therefore, the Lorentz force density can be decomposed into,

$$
\begin{aligned}
& f_{r}=J_{p h i} \cdot B_{z} \\
& f_{z}=-J_{p h i} \cdot B_{r}
\end{aligned}
$$

where $f_{r}$ and $f_{z}$ are radial and axial component of the Lorentz force density, separately.

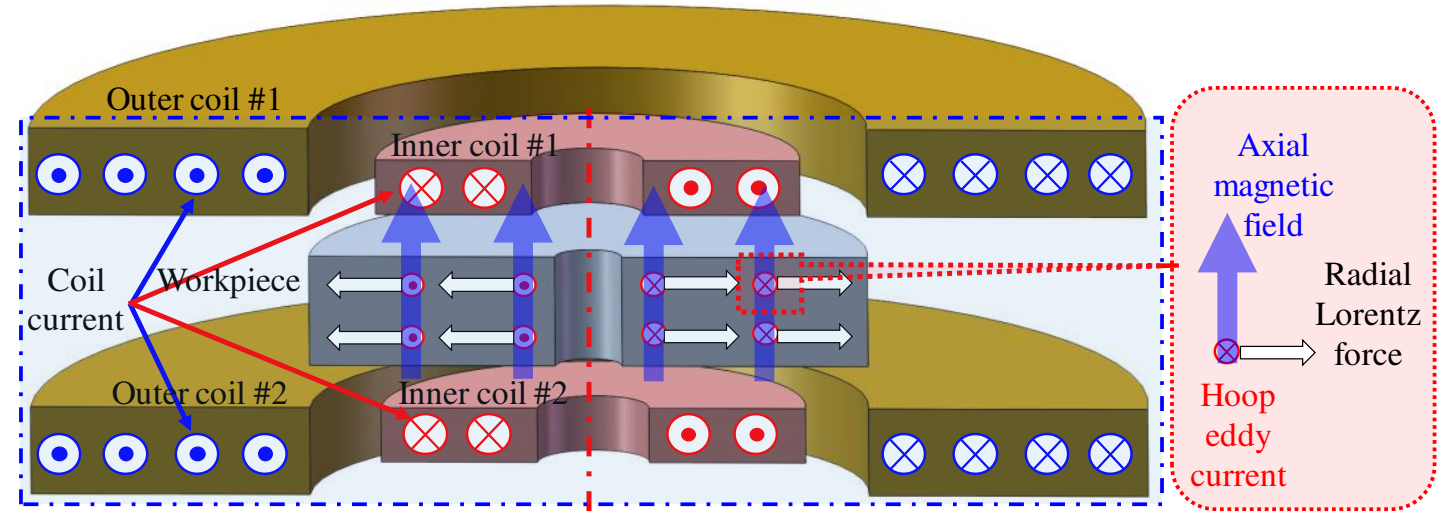

Fig. 1 Schematic of electromagnetic cold expansion system

Same as the conventional hole strengthening, the EMCE requires a radial outward force inside the workpiece to deform and exceed the yielding point of the workpiece. Here, instead of a facial force directly applied onto the hole wall like the split sleeve method, this force is a non-contact body force during EMCE. The schematic drawing of the EMCE system in this work is presented in Fig. 1. The system mainly consists of 
two sets of coils, named the inner coil and the outer coil, and each set of coils are in series connection. The outer coil is mainly used to introduce a relatively constant axial magnetic field during the EMCE process, while the inner coil is mainly used to generate a strong enough eddy current in the workpiece. All the coils and the hole of the workpiece are placed coaxially.

The discharge currents of the coils are shown in Fig. 2, which consist of a long pulse width current and a short pulse width current, the former is applied into the outer coils, and the latter is applied into the inner one. The inner coil current is triggered and reaches its peak value within tens of microseconds when the current in the outer coil reaches its maximum value.

Now Eqn. (2) could be rewritten as

$$
f_{r}=\left(J_{\text {phi_long }}+J_{\text {phi_short }}\right) \cdot\left(B_{z_{-} \text {long }}+B_{z_{-} \text {short }}\right) \text {, }
$$

in which $J_{\text {phi_long }}$ and $J_{\text {phi_short }}$ are respectively the eddy current induced by the outer coil and the inner coil, $B_{z_{-} l o n g}$ and $B_{z_{-} \text {short }}$ are the axial magnetic field generated by the outer coil and the inner coil, separately.

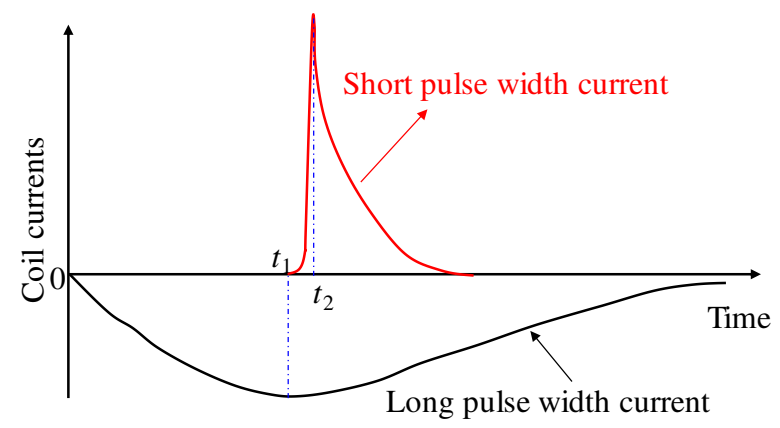

Fig. 2 Schematic of the coil currents

It should be noticed that, $t_{1} \gg t_{2}-t_{1}$, say, the rising time of inner current is much shorter than that of the outer current, and the peak value of the inner coil current is 
higher than that for the outer coil, so $J_{\text {phi_short }} \gg J_{\text {phi_long }}$. Though the inner coil current is higher, the number of turns of the outer coil could be several times of that for the inner coil, so the axial magnetic field keeps it direction during the whole EMCE process. The schematic diagrams of the axial magnetic field and the eddy current are given below.

With such a design of the coils and the discharge currents, Eqn. (4) could be

$$
f_{r} \approx J_{\text {phi_short }} \cdot B_{z_{-} \text {long }}
$$

say, the outer coil mainly aims at providing a proper background axial magnetic field while the inner coil is responsible for exciting a strong enough eddy current in the workpiece. And the decoupling design of the two sets of coils can generate the Lorentz force needed for EMCE.
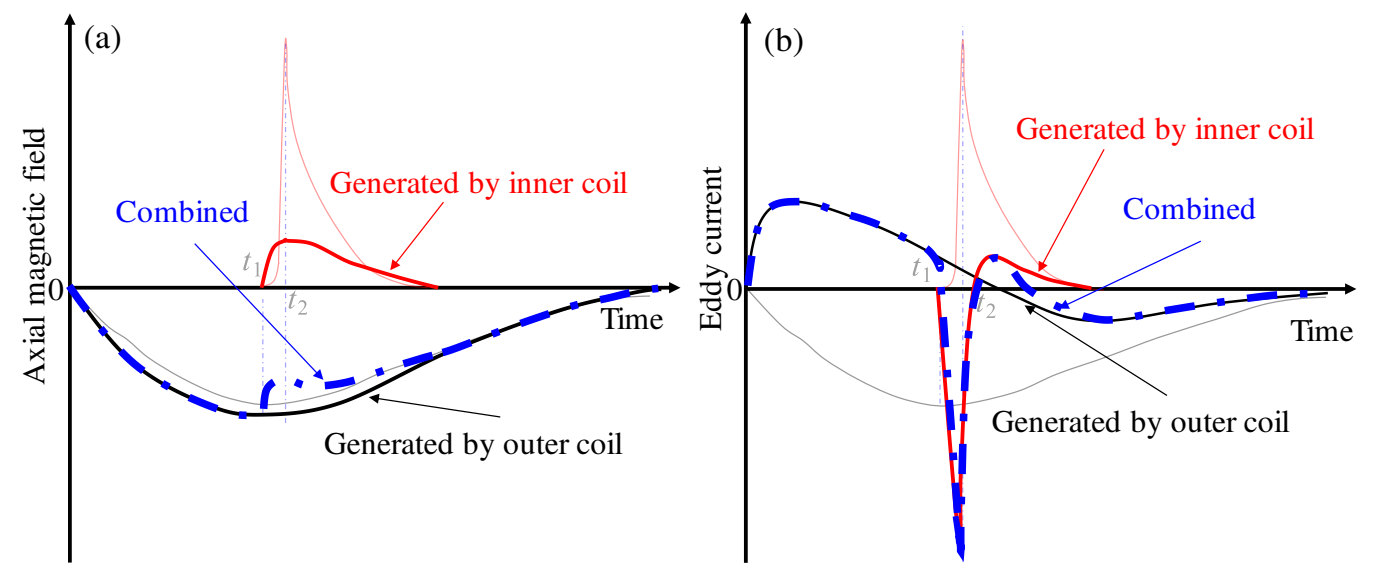

Fig. 3 Schematic diagram of the expected (a) axial magnetic field and (b) eddy current, the background transparent lines show the discharge current

\section{Materials, experiment and simulation details}

\subsection{Material}

In this research, two $1.5 \mathrm{~mm}$-thick circular plates of 2A12-T4 aluminum alloy 
(Chinese standard, GB) plate with the diameter of $50.0 \mathrm{~mm}$ were adopted to measure the radial strain of the material after EMCE. Rectangle plates with the size of 50.0 $\mathrm{mm} * 200.0 \mathrm{~mm}$ were utilized to conduct the fatigue life test. The material used here is widely used in aerospace industry owing to the high strength, excellent corrosion resistance ect. A hole was drilled and carefully reamed to a final diameter of $6.0 \mathrm{~mm}$ at the center of all of the plates.

The chemical compositions of 2A12-T4 in this research was listed in Table 1 . The mechanical property was tested through a uni-axial tensile test, given in Fig. 4 . The $0.2 \%$ proof stress, modulus of elasticity and the poisson's ratio were $262 \mathrm{MPa}, 73 \mathrm{GPa}$ and 0.33 , respectively.

Table 1 Chemical composition of 2A12-T4

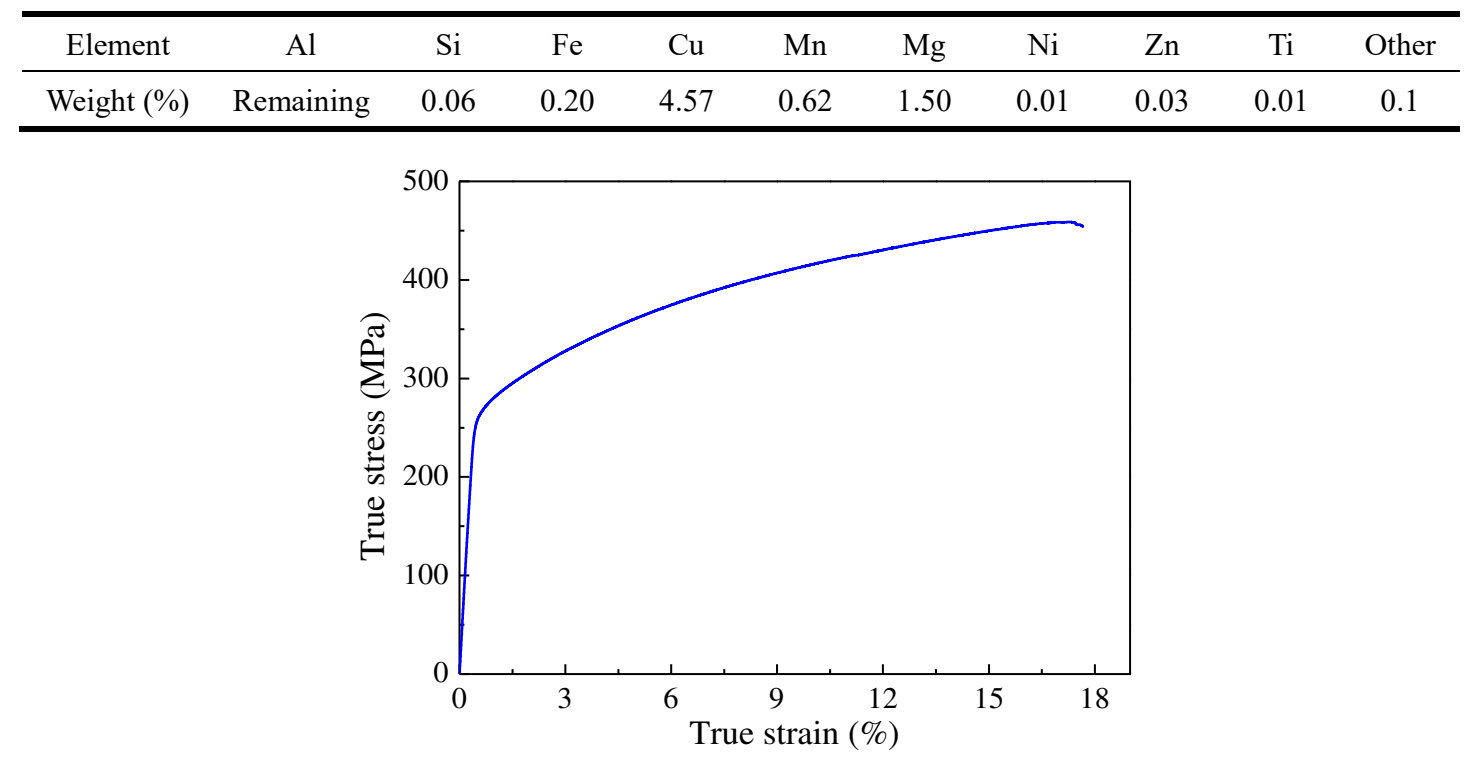

Fig. 4 The tested stress-strain curve of the material (2A12-T4)

The Johnson-Cook constitutive model was adopted in this study to reflect the response of the 2A12-T4 plate under high strain rate due to the pulsed electromagnetic force. Without consideration of the temperature increase in a single discharge process, 
which often led to $20-30{ }^{\circ} \mathrm{C}$ of the temperature increase, the Johnson-Cook constitutive model is described as,

$$
\sigma=\left(A+B \varepsilon_{e f f}^{n}\right)\left[1+C \ln \left(\varepsilon_{p e}^{\cdot}\right)\right]
$$

the detailed value of each parameter is presented in Table 2.

Table 2 Parameters used in Johnson-Cook constitutive model without considering the temperature

\begin{tabular}{ccc}
\hline & Property & Value \\
\hline$A$ & Initial yield stress (MPa) & 262.0 \\
$B$ & Hardening constant (MPa) & 561.0906 \\
$\varepsilon_{e f f}$ & Effective plastic strain & - \\
$n$ & Hardening exponent & 0.5600 \\
$C$ & Strain rate constant & $0.0083[26]$ \\
$\varepsilon_{p e}$ & normalized effective plastic strain rate & - \\
\hline
\end{tabular}

\subsection{Design and implementation}

The specific circuit model was presented in Fig. 5. The system consisted of two sets of coils, driven by two independent power supplies. The time accuracy of the two power supply discharges was controlled at $0.1 \mu$ s level to generate a proper Lorentz force. It is to be noted that there is a crowbar branch consisting of a crowbar resistance and a diode in each discharge circuit, which can be used to alter the waveforms of the discharge current through adjusting the crowbar resistance [27]. Details of the parameters for the two discharge circuits were presented in Table 3.

To enhance the fatigue life of the coil sets, the zylon fiber, which actually has a strength of $4 \mathrm{GPa}$, was used as the reinforcing fiber during the fabrication process of the coils. The outer coil, which was expanded due to the Lorentz force, was strengthened layer by later. While the inner coil, that was compressed during the EMCE process, was strengthened at the outermost layer. The assembly of the coils and the 
specimen was given below. To eliminate the friction between the coil sets and the sample as well as to avoid the surface scratch of the sample during its deformation, the sample was covered with Polyethylene thin film and a set of holders with the thickness of $1.8 \mathrm{~mm}$ were used.

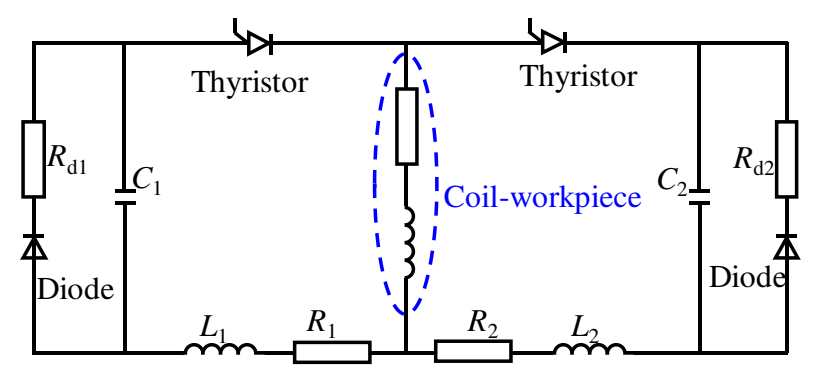

Fig. 5 Schematic diagram of the electrical circuit of the EMCE system

Table 3 Circuit parameters

\begin{tabular}{ccc}
\hline & Inner coil system & Outer coil system \\
\hline Initial discharge voltage & $\mathrm{U}_{1}=4 \mathrm{kV}$ & $\mathrm{U}_{2}=6 \mathrm{kV}$ \\
Initial capacitance & $\mathrm{C}_{1}=160 \mu \mathrm{F}$ & $\mathrm{C}_{2}=3.2 \mathrm{mF}$ \\
Line inductance & $\mathrm{L}_{1}=8 \mu \mathrm{H}$ & $\mathrm{L}_{2}=700 \mu \mathrm{H}$ \\
Line resistance & $\mathrm{R}_{1}=8 \mathrm{~m} \Omega$ & $\mathrm{R}_{2}=180 \mathrm{~m} \Omega$ \\
Crowbar resistance & $\mathrm{R}_{\mathrm{d} 1}=7 \mathrm{~m} \Omega$ & $\mathrm{R}_{\mathrm{d} 2}=3.5 \Omega$ \\
Triger moment & $4.7 \mathrm{~ms}$ & $0 \mathrm{~ms}$ \\
\hline
\end{tabular}
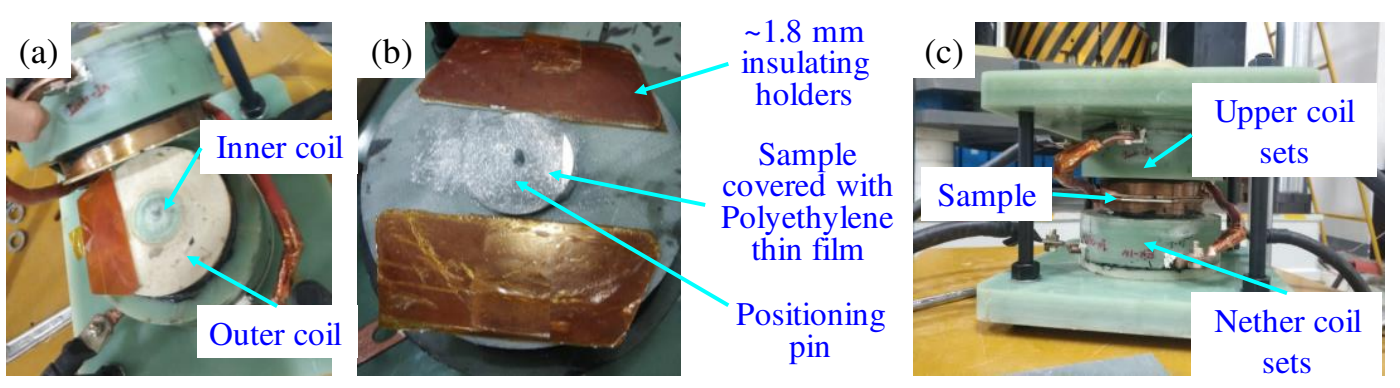

Fig. 6 The assembling of the EMCE system: (a) the coil sets, (b) the holders and Polyethylene thin film used and (c) the coil sets and specimen

\subsection{Grid method}

To obtain enough data near the hole with grid method, the grid had to be small enough, and the grid boundary had to be clear enough under the microscope. In this 
paper, the grids were etched by a 4 watt YAG laser and placed in a $80 \times 80$ matrix, with a diameter of $300 \mu \mathrm{m}$ for each grid and a distance between grids were $200 \mu \mathrm{m}$, given in Fig. 7(a).

As shown in Fig. 7(b), the deformation of the grid was measured using the Nikon SMZ18 optics microscope. Fig. 7(c) presented the deformed grid transformed from a circle to ellipses near the hole wall on the specimen. The initial gird size was determined via taking the average diameter of 10 grids, and the size of the grid along radial direction was measured again after EMCE. Then, the radial strain of the specimen could be calculated via

$$
\varepsilon_{r}=\ln \left(d_{1} / d_{0}\right)
$$

in which $\varepsilon_{r}$ was the radial strain, $d_{1}$ and $d_{0}$ were the deformed and original grid diameter, separately. To make the measurement accurate, the residual radial strains were measured for three times along three mutually perpendicular routes.
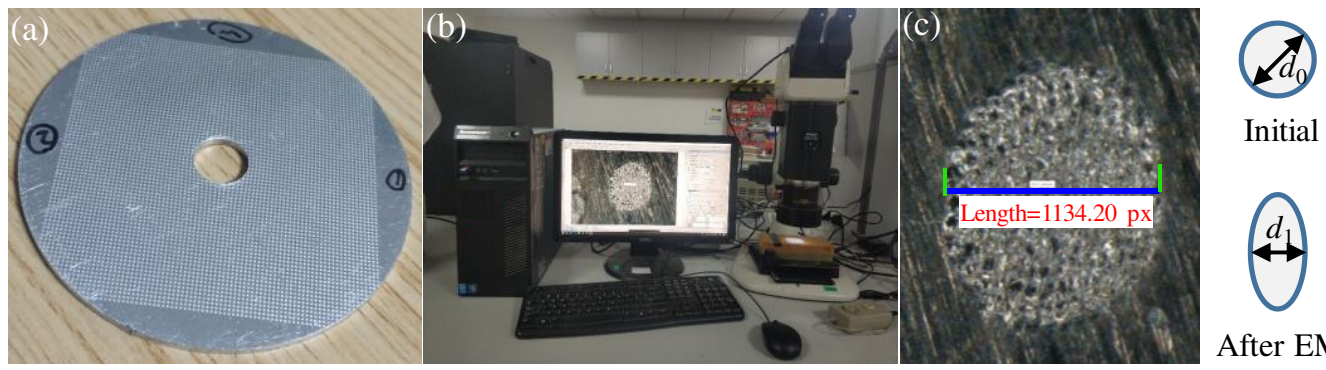

After EMCE

Fig. 7 Deformation measurement of the EMCE specimen: (a) the microgrids etched on the specimen,

(b) the test platform and (c) the deformed grid

\subsection{Fatigue test}

A total of 40 specimens (20 'as drilled' and 20 EMCE specimens) were tested in fatigue at room temperature. The cyclic tension-tension loading test was implanted 
using a high-frequency electromagnetic resonance fatigue testing machine (QBG-50) with a stress ratio of 0.1 , and the resonance frequency was about $105 \mathrm{~Hz}$. The maximum nominal net section stress levels were set to be $120 \mathrm{MPa}, 140 \mathrm{MPa}, 160 \mathrm{MP}$ and $180 \mathrm{MPa}$. The fatigue test platform was given below.

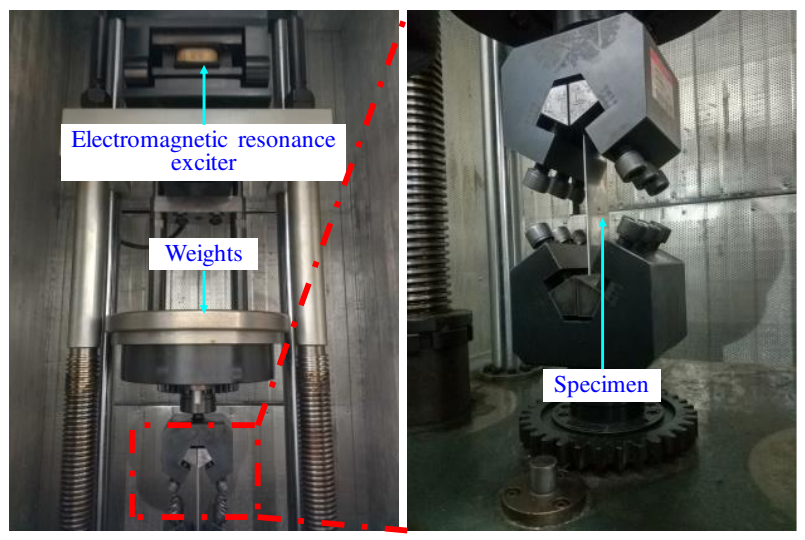

Fig. 8 High frequency fatigue life test platform

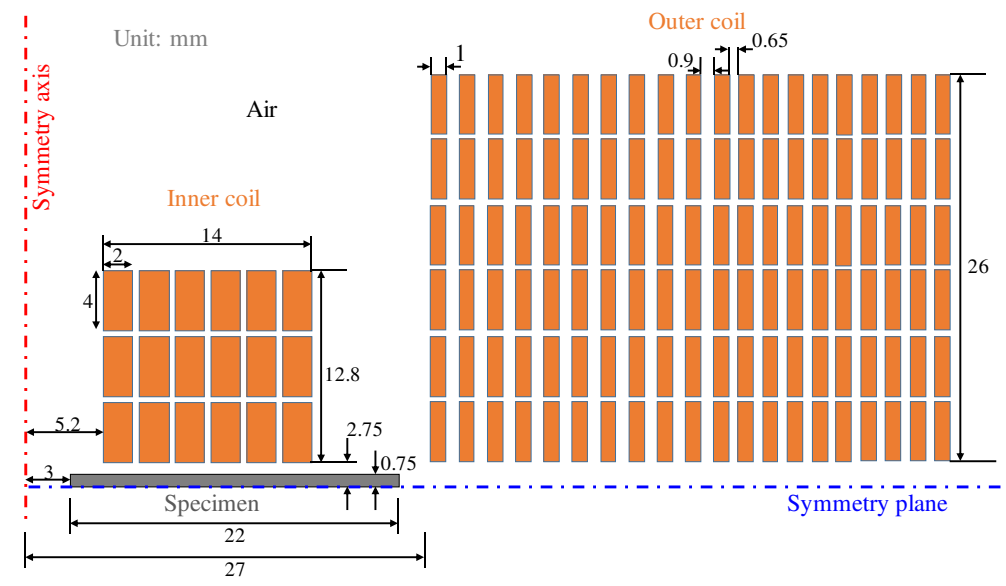

Fig. 9 Detailed geometric parameters of the EMCE coils and specimen from a quarter section view

\subsection{Finite element simulation}

In this study, a 2D axisymmetric full-coupled numerical simulation model was developed via COMSOL Multiphysics. The electromagnetic field, the solid mechanics field, and the ODEs were utilized to solve the coupling equations of the electromagnetic field and solid mechanics field, as well as to solve the RLC circuit equations shown in 
Fig. 5. The computational model was presented in Fig. 9, and it mainly consisted of the circuits, the coils and the specimen.

\section{Results and discussion}

To investigate the influence of the EMCE parameters on the PDZs in thin 2A12T4 plate, the deformation of the specimens was investigated both numerically and experimentally.

\subsection{Validation of the finite element simulation}

The discharge current of the two coils were separately detected by a Rogowski coil and a Pearson current transformer. Fig. 10 shows both the detected and simulated coil currents, showing a good agreement between the two results. It can be seen that the pulse width of the outer coil was longer, while it was short for the inner coil. The long pulse width current reached its peak value at $4.70 \mathrm{~ms}$, meanwhile, the power supply for the inner coil system was triggered, and the corresponding current reached its maximum value in $98 \mu \mathrm{s}$. It should be mentioned that the crowbar branch was short circuited to realize a small enough crowbar resistance. Then there was an oscillation attenuation waveform of the inner coil in the experiment, which was mainly owing to the small enough inductance in the shorted-circuited crowbar circuit. This is neglectable as discussed in Appendix A.

Fig. 11 shows the residual radial strain obtained by the grid method and the FEM simulation. The simulation results match with the experiments well, for that the compressive radial strain is at its maximum value near the hole wall, and then decreases sharply away from the hole wall within $4 \mathrm{~mm}$, after that, the strain remains around zero. 
The strain gradient is very high near the hole wall, though the physical size of the etched grids limits the measurement accuracy of the strain at these high-gradient areas, the total trend as well as the magnitude of the residual strain between the two results shows a comparable result.

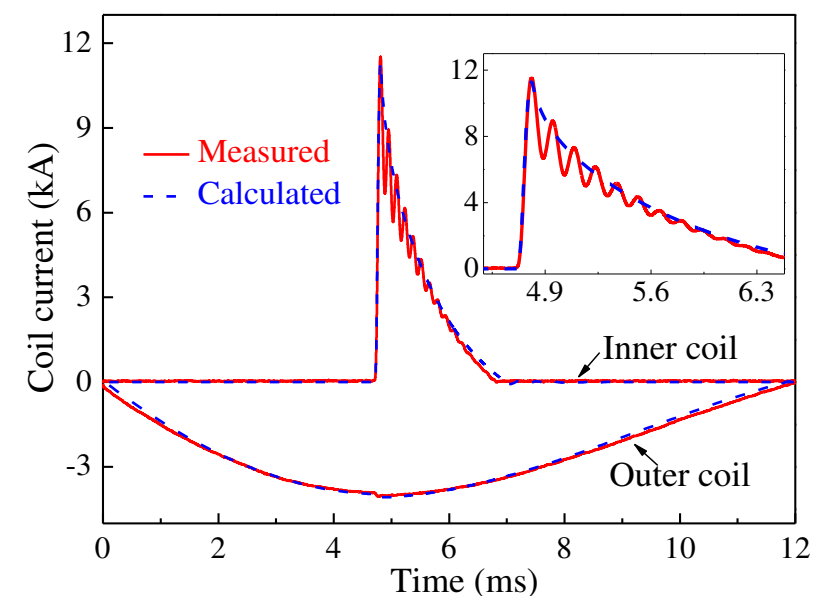

Fig. 10 The coil currents comparison between the FEM simulation and the experiment when $\mathrm{U}_{1}=4 \mathrm{kV}, \mathrm{U}_{2}=6 \mathrm{kV}$
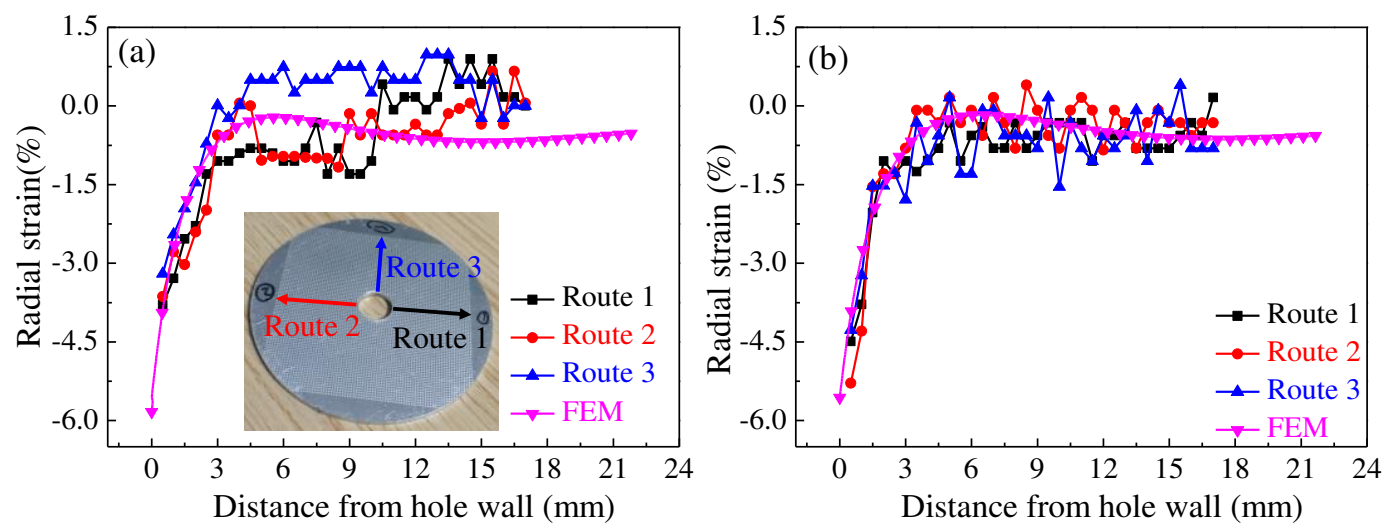

Fig. 11 The residual radial strains under different discharge voltages: (a) $\mathrm{U}_{1}=4 \mathrm{kV}, \mathrm{U}_{2}=6 \mathrm{kV}$, (b) $\mathrm{U}_{1}=4.5 \mathrm{kV}, \mathrm{U}_{2}=5 \mathrm{kV}$

It must be stated that, during EMCE process, very few parameters, including discharge current and the final residual strain, could be experimentally obtained, and these obtained results were in good agreement with the 2D axisymmetric FEM 
simulations. Considering that this paper is mainly at clarifying that, the EMCE could induce a considerable PDZ in thin Al alloy fasteners with holes and the PDZs can be affected by the circuit parameters, the following analysis were mainly further performed based on FEM simulations.

\subsection{Distribution of residual stress}

Fig. 12(a) presents the Lorentz force inside the Al plate during the EMCE process. It is obvious that, a considerable Lorentz force arose only when the power supply for the inner coil was triggered. When $t<4.672 \mathrm{~ms}$ and $\mathrm{t}>4.958 \mathrm{~ms}$, the value of radial Lorentz force component was less than one-tenth of the that at $\mathrm{t}=4.740 \mathrm{~ms}$. The Lorentz force required to yield the Al plate should be induced by a hoop eddy current and an axial magnetic flux density. Fig. 12(b) gives the spatial distribution of the eddy current density, the magnetic field and the Lorentz force density. As previously designed, the magnetic field was mainly oriented along the axial direction (downward), and the eddy current was along the hoop direction (clockwise), finally, the magnetic field was radially outward. Though there existed axially downward Lorentz force component near the plate boundary as shown in Fig. 12(b), the plane-symmetry of the geometry eliminated the net axially downward Lorentz force to zero.

The eddy current and axial magnetic flux density at point $\mathrm{A}((13.7,0)$, see Fig. 12(a), $t=4.740 \mathrm{~ms}$ ) are shown in Fig. 13(a). It is obviously that, the eddy current reaches its negative peak value at $4.740 \mathrm{~ms}$ (set clockwise as positive), and the upward axial magnetic flux (negative) is maximum. Therefore, a considerable radial Lorentz force is generated at point A, shown in Fig. 13(b). 



Fig. 12 (a) Distribution of the radial Lorentz force component and Lorentz force vectors inside the plate during the EMCE process. (b) Distribution of the eddy current density (color), magnetic field vectors (red arrows) and Lorentz force density vectors (white arrows) at $\mathrm{t}=4.740 \mathrm{~ms}$
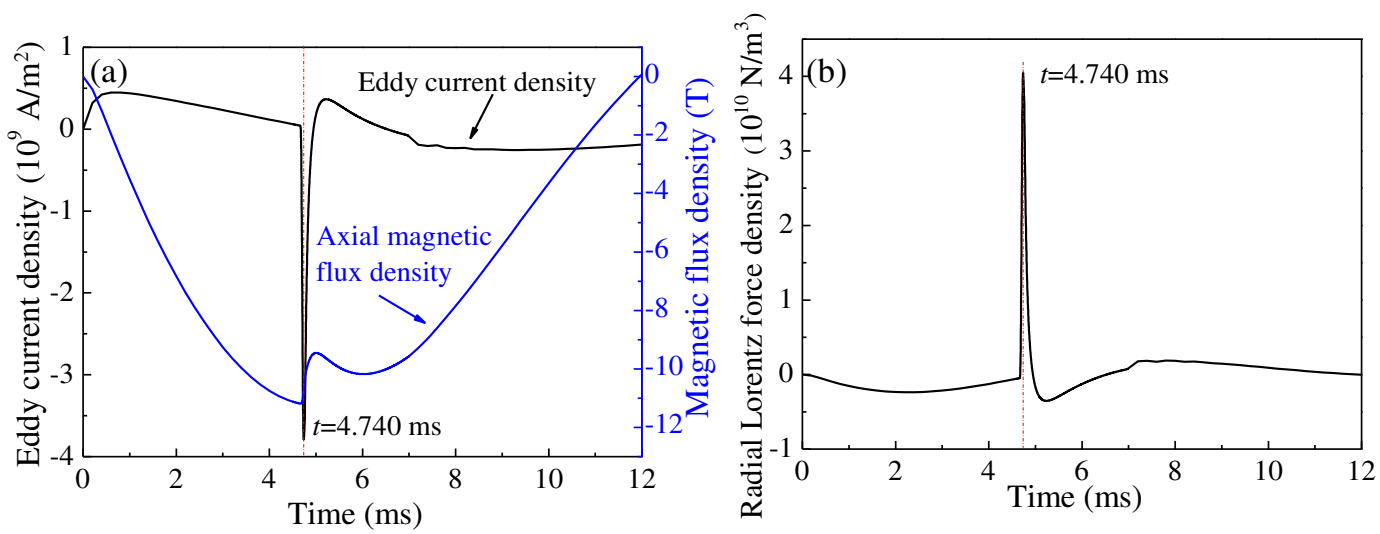

Fig. 13 (a) The eddy current density and axial magnetic flux density and (b) radial Lorentz force density at point $\mathrm{A}$

The relationship between von Mises stress and the yield stress can be used to determine the PDZ, i.e., the boundary of PDZ is the point where the von Mises stress is equal to the yield stress [8]. The reason why the area closed to the hole wall possess higher von Mises stress was owing to the huge hoop tensile stress, as presented in Fig. 14(a). For the EMCE process, the stress for both the radial and hoop direction were tensile, and this is quite different from the conventional hole-wall-push cold working 
method. For those conventional method, the stress is tensile along hoop direction, but is compressive in the radial direction, this stress state is easily to cause local wrinkle or volcano near holes in thin sheets. However, in EMCE process, this can be avoided for the tensile stress in both hoop and radial directions.
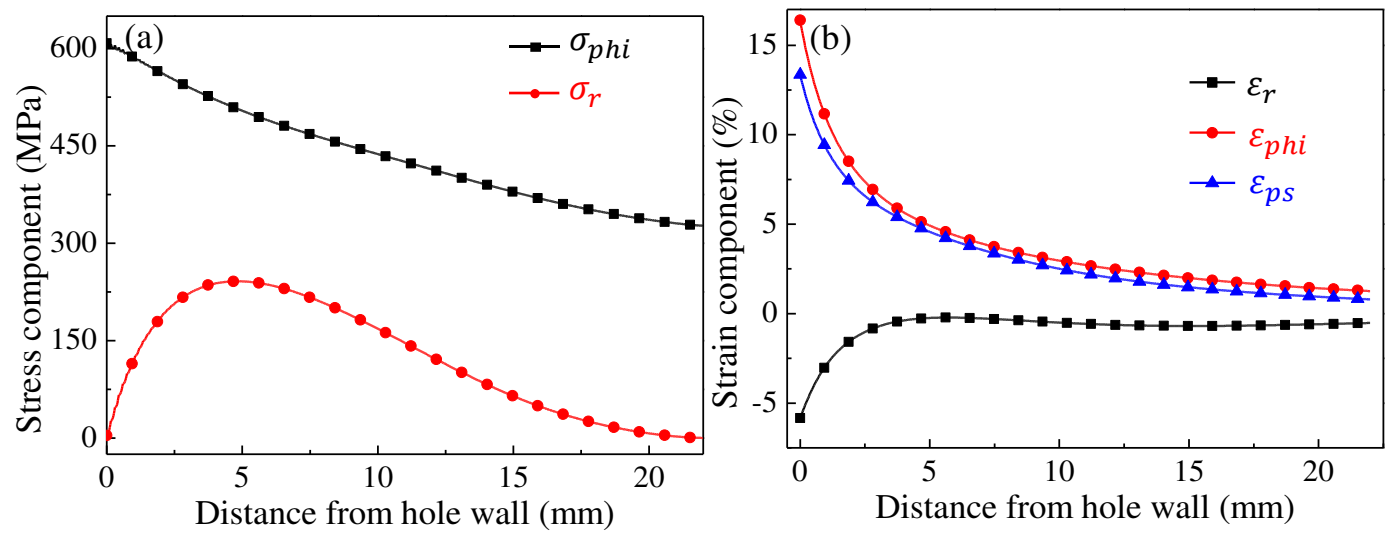

Fig. 14 (a) Stress components at $\mathrm{z}=0 \mathrm{~mm}$ at $\mathrm{t}=4.740 \mathrm{~ms}$. (b) The residual hoop strain after the EMCE process at $\mathrm{z}=0 \mathrm{~mm}\left(\varepsilon_{p s}\right.$ is the effective plastic strain)
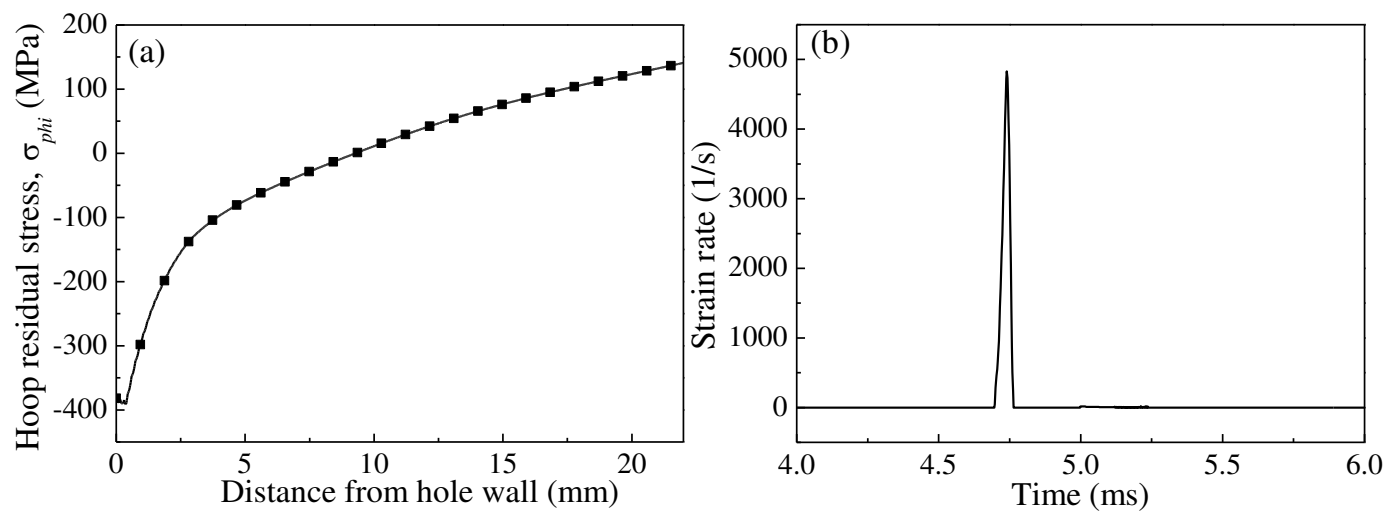

Fig. 15 (a) The residual hoop stress after the EMCE process at $z=0 \mathrm{~mm}$. (b) Huge strain rate during the EMCE process at the hole wall

The EMCE process introduces a non-uniform stress field along the radial direction, resulting in a non-uniform elastic and plastic deformation field. The radial strain near the hole wall is higher than that at the outer area of the specimen, as shown in Fig. 14(b). 
After EMCE process, as the radially outward Lorentz force is removed, the material near the hole wall is constrained by the outer material, and thus, the residual compressive stress is produced, as shown in Fig. 15(a). As stated above, the electromagnetic process introduces a very high strain rate, shown in Fig. 15(b). The high strain rate is sufficient to harden the material, making it show a completely different constitutive relationship compared with the quasi-static state.

\subsection{Effect of the pulse width of the inner coil current}

As discussed above, the main reason for the producing of the residual stress was the axial magnetic flux density and the hoop eddy current. Owing to its longer pulse width, the former remains nearly constant during the whole discharge process of the inner coil, so it has little effect on the final residual stress. The eddy current, however, is largely influenced by the pulse width of the inner coil, therefore, it would be an effective way to tune the PZD via varying the pulse width of the inner coil. In the following, a series of simulations focused on different pulse width of the inner coil were conducted, while the total energy for the inner coil discharge system was set to be constant $(1150 \mathrm{~J})$.

Fig. 16 shows the maximum von Mises stress distribution during each discharge process and the correlation between short pulse width and the size of PDZ. Here, a cutting line of $\mathrm{z}=0 \mathrm{~mm}$ was chosen, which represented the middle plane of the plate and the axial Lorentz force was ignorable. It could be observed that, the larger capacitance, the wider the pulse width. However, the size of plastic deformation shows a nonmonotonic relationship with the capacitance. When the capacitance was larger than 
$40 \mu \mathrm{F}$, the size of PDZ increased with a decreasing capacitance, but it decreased as the capacitance was further decreased below $40 \mu \mathrm{F}$. In addition, it also could be observed that, when the width of the short pulse current $\left(W_{s}\right)$ was $64 \mu \mathrm{s}$, nearly all the plate area was plastically deformed, however, there was little PDZ when $W_{s}=170 \mu \mathrm{s}$. This indicates that, the Lorentz force is too weak when the width of the coil current was too long, and this is mainly owing to the induced weak eddy current inside the workpiece.
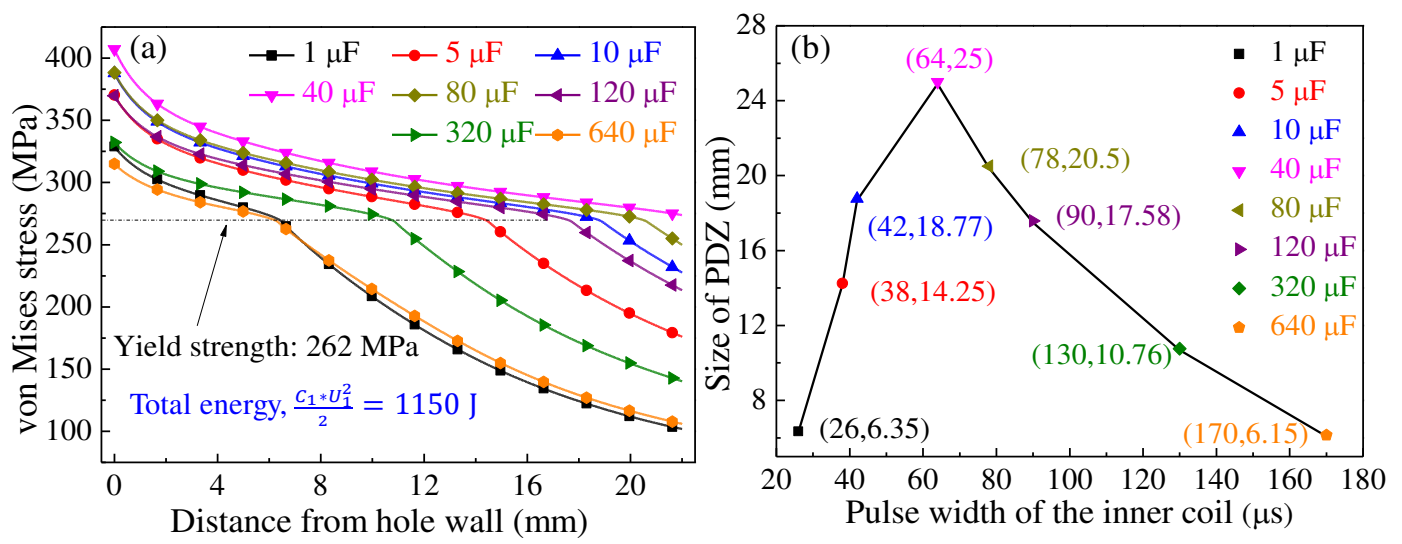

Fig. 16 (a) The maximum von Mises stress distribution at $\mathrm{z}=0 \mathrm{~mm}$. (b) The relationship between short pulse width and the size of the PDZ

The reason why the size of PDZ decreased with a sharper pulse width as the capacitance was smaller than $40 \mu \mathrm{F}$ could be given in Fig. $17(\mathrm{a})$. When $\mathrm{C}_{1}>40 \mu \mathrm{F}$, the discharge current increased slowly as the capacitance decreased, and the larger PDZ was mainly contributed by a shorter pulse width. However, as $\mathrm{C}_{1}<40 \mu \mathrm{F}$, the situation became quite complicated. On the one hand, the pulse width was further shortened, which was beneficial for the EMCE process, on the other hand, the discharge current decayed dramatically. This change could be attributed to the response of inductive reactance and the circuits resistance under high frequency pulsed current, as presented in the appendix A. 
The corresponding hoop residual stress after the EMCE process is plotted in Fig. 17(b). As the capacitance decreased, the compressive hoop residual stress near the hole wall was firstly increased and then decreased, and reached its maximum value when $\mathrm{C}_{1}=40 \mu \mathrm{F}$. This trend was coincidence with the results of the size of PDZ.
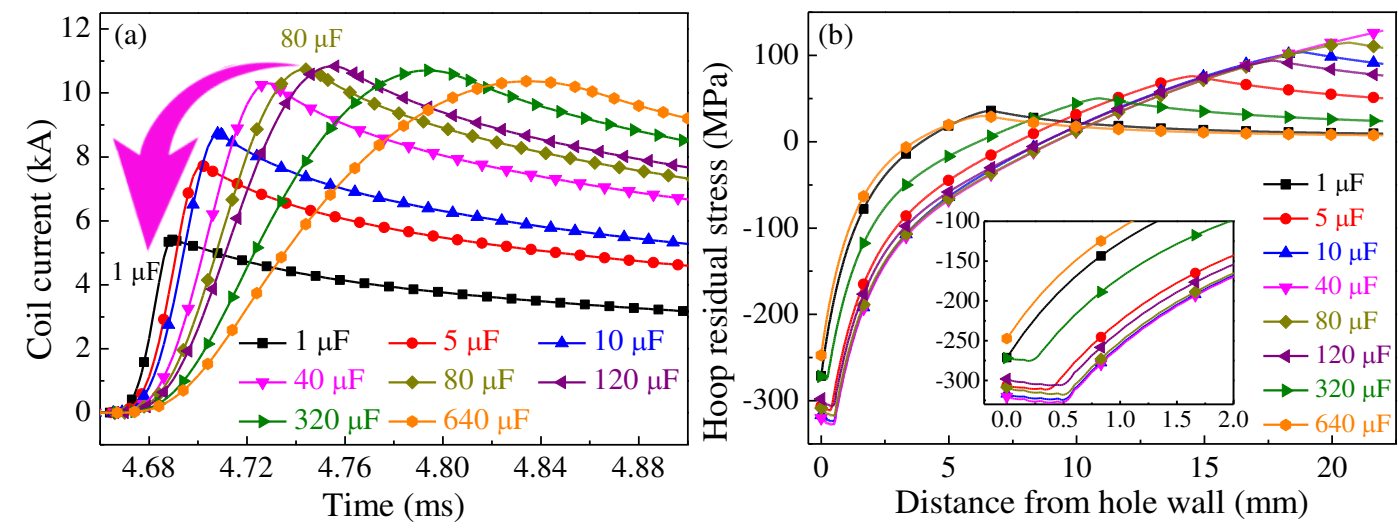

Fig. 17 Simulated results under different discharge conditions: (a) the inner coil current, and (b) the hoop residual stress at $\mathrm{z}=0 \mathrm{~mm}$

\subsection{Effect of the crowbar resistance}

The crowbar resistance of the inner coil took into effect during the unloading process, and it did not influence the size of PDZ, but had a great impact on the final residual stress. A larger crowbar resistance resulted in a sharper decrease of the coil current, as shown in Fig. 18.

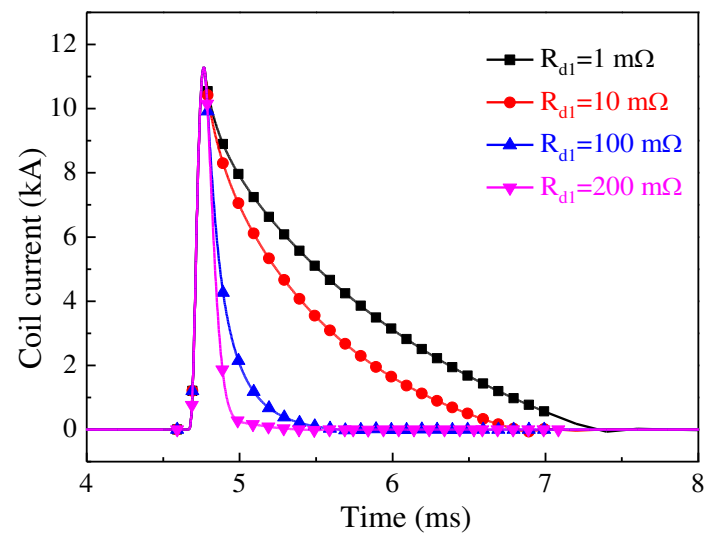

Fig. 18 The inner coil current with varied crowbar resistance 
To investigate the effect of crowbar resistance, the discharge current of the inner coil for $R_{\mathrm{d} 1}=1 \mathrm{~m} \Omega$ and $200 \mathrm{~m} \Omega$ were compared. Five feature points on each current curve are picked, as shown in Fig. 19(b), they are corresponding to, before the inner coil is discharged (A and $A^{\prime}$ ), the radially outward (positive) Lorentz force is maximum ( $\mathrm{B}$ and $\left.\mathrm{B}^{\prime}\right)$, the radially Lorentz force is minimum $\left(\mathrm{C}\right.$ and $\left.\mathrm{C}^{\prime}\right)$, the radially inward (negative) Lorentz force is maximum ( $\mathrm{D}$ and $\mathrm{D}^{\prime}$ ) and the radially Lorentz force is minimum again ( $\mathrm{E}$ and $\left.\mathrm{E}^{\prime}\right)$. The corresponding eddy current, axial magnetic flux density and radial Lorentz force density at each point are plotted in Fig. 20, which also roughly reflects the whole EMCE process. The axial magnetic flux density was mainly negative during the whole process, and did not contribute to the reversed radial Lorentz force. Although the axial magnetic flux density was partially reversed near the hole wall, see C, D and $\mathrm{D}^{\prime}$, the eddy current at those area was too weak, and the corresponding Lorentz force was ignorable. The eddy current reversed at $\mathrm{D}$ and $\mathrm{D}^{\prime}$, and this led the Lorentz force density radially inward. In addition, a higher crowbar resistance led to a higher reversed eddy current, meanwhile, the axial magnetic field was stronger, thus leading to a stronger radially inward Lorentz force density.

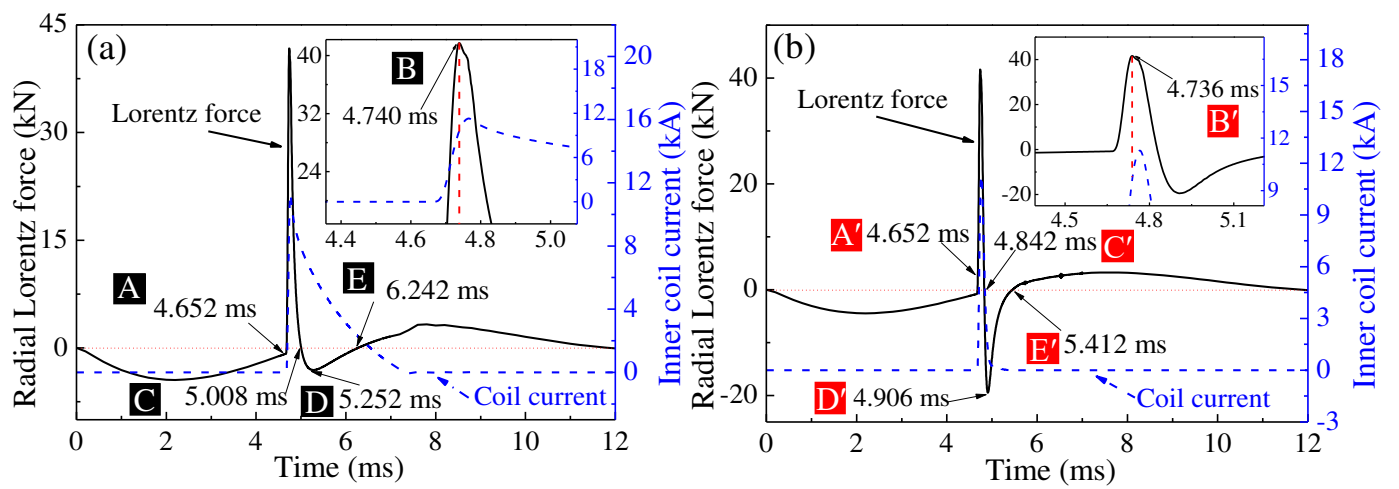

Fig. 19 The radial Lorentz force at the five specific time points during the EMCE process when (a) $\mathrm{R}_{\mathrm{d} 1}=1 \mathrm{~m} \Omega$, (b) $\mathrm{R}_{\mathrm{d} 1}=200 \mathrm{~m} \Omega$ 


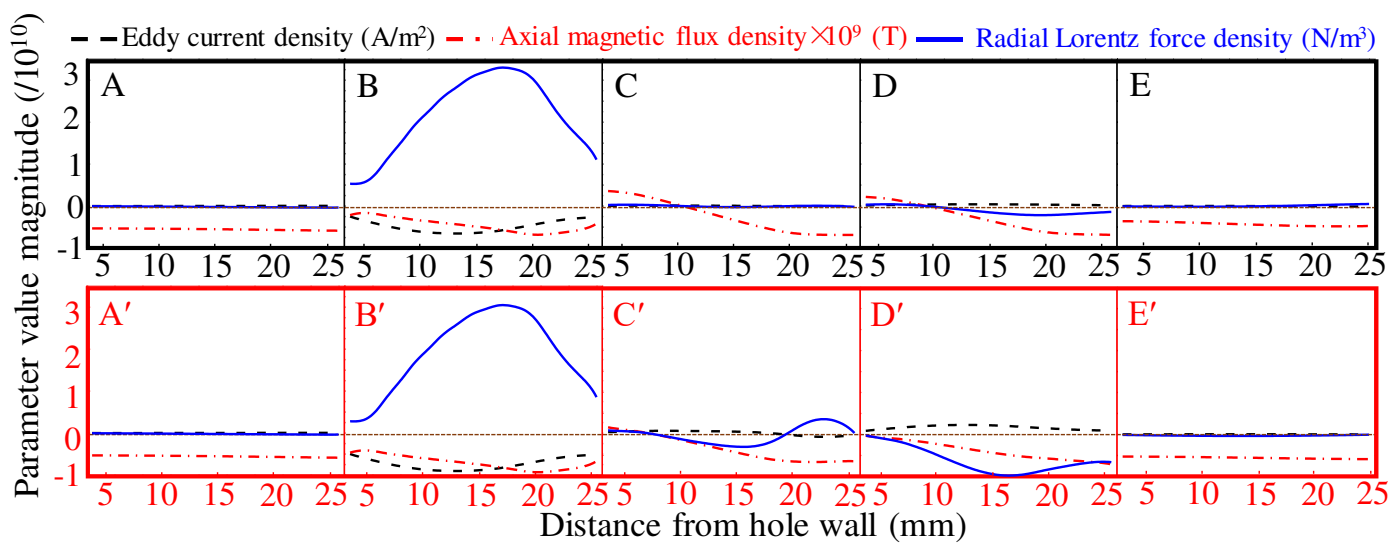

Fig. 20 The eddy current, axial magnetic flux density and radial Lorentz force density during the EMCE process when $\mathrm{Rd} 1=1 \mathrm{~m} \Omega$ (top row) and $200 \mathrm{~m} \Omega$ (bottom row), at $\mathrm{z}=0$. To make the values of axial magnetic flux density comparable, its value was expanded by $10^{9}$ times

The final hoop residual stress is given in Fig. 21. It can be observed that, even the sizes of PDZ under the maximum load are the same, the final residual stresses are quite different. The larger crowbar resistance, the smaller hoop residual stress. This means that, the reversed Lorentz force has a significant influence on the formation of the final residual stress. Besides, for the region near the hole wall, there is a slight decrease of the compressive residual stress, and it is much more obvious when the crowbar resistance is larger. This might be attributed to that the reversed Lorentz force, which located at the middle region between the hole wall and the plate edge far from the hole wall, is higher when the crowbar resistance is larger. The decrease of the compressive residual stress near the hole wall is not a preference for hole strengthening, for the fatigue cracks were mainly initiated at the hole wall. This is also the reason why the crowbar circuit of the inner-coil discharge system was shorted, as stated in Section 4.1. 


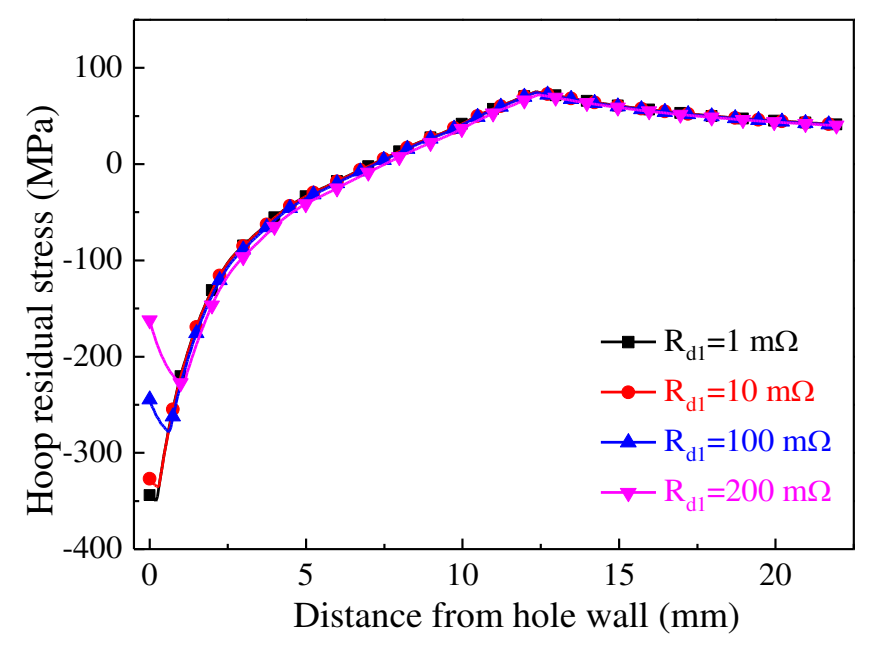

Fig. 21 The hoop residual stress under different crowbar resistance of the inner-coil circuit at $\mathrm{z}=0 \mathrm{~mm}$

\subsection{Fatigue test after EMCE}

The fatigue life comparison between the 'as-drilled' and the EMCE strengthened fasteners is given below. A significant enhancement of the fatigue life is achieved after the EMCE. The gain in fatigue life depends on the maximum applied stress, and they are 5.49, 3.50, 2.51 and 1.67 times when the maximum applied stress are $120 \mathrm{MPa}$, $140 \mathrm{MPa}, 160 \mathrm{MPa}$ and $180 \mathrm{MPa}$, respectively.

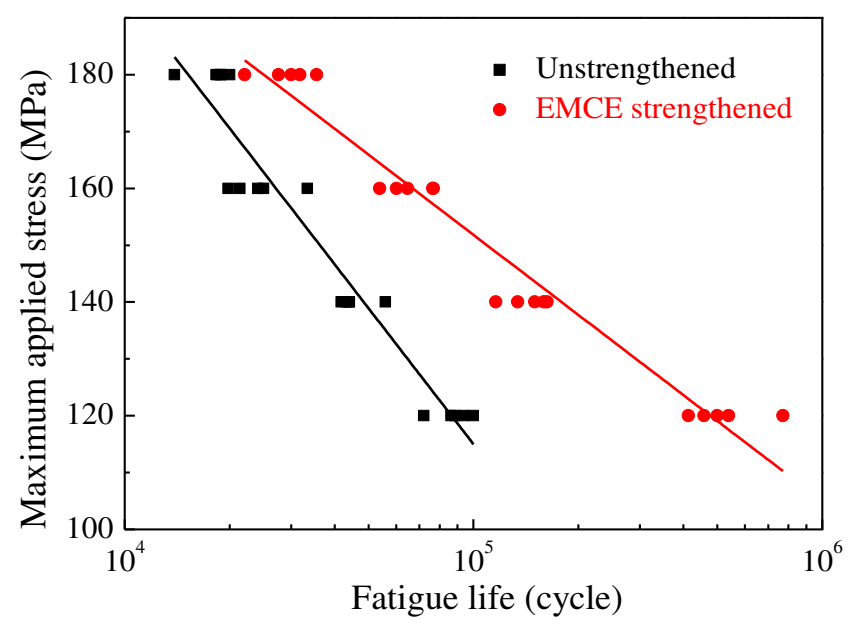

Fig. 22 The S-N curve comparison of the specimens for unstrengthened and EMCE strengthened 


\section{Conclusions}

In this study, a dual-coil electromagnetic cold expansion method was used to introduce a tunable PDZ in a $1.5 \mathrm{~mm}$-thick $2 \mathrm{~A} 14-\mathrm{T} 4$ plate. The influence of the circuit parameters on the size of plastic deformation zone as well as the residual stress was analyzed. The following conclusions are drawn.

(1) The electromagnetic method utilized radial Lorentz force to drive the material deform plastically/elastically. It was tensile for both radial and hoop stress component during the electromagnetic process. In addition, there was no axial force during electromagnetic cold expansion.

(2) The electromagnetic method caused inhomogeneous radial strain along the radial direction, and the strain gradient near the hole wall was very high. The radial strain component was about $6 \%$ at the hole wall, but decayed dramatically and was about $1 \%$ when it was $3 \mathrm{~mm}$ from the hole wall.

(3) A large PDZ was introduced and extended to the whole body of a $1.5 \mathrm{~mm}$ thick plate with the diameter of $50 \mathrm{~mm}$. A considerable residual compressive stress was formed even the whole plate was plastically deformed.

(4) The relationship between the short pulse width and the size of PDZ was nonmonotonic, and the most suitable capacitance in this study was $40 \mu \mathrm{F}$. For a higher or lower capacitance, the generated eddy current was weak owing to the longer pulse width or lower current magnitude in the coil.

(5) The radially inward force during unloading stage should be as weak as possible, and the crowbar resistance should be short-circuited. The oscillation current 
waveform for a short-circuited crowbar resistance circuit didn't have an important impact on the final stress state of the plate.

Overall, the obtained results clearly showed that, the EMCE method was very effective in strengthening the thin fastener with holes. It can make up for the deficiency of serious axial deformation and small plastic area caused by the traditional method when strengthening thin specimen with holes.

\section{Appendix A}

The author has fitted the detected oscillation attenuation waveform for the inner coil current and substituted it to FEM, and compared with the situation when this oscillation attenuation waveform was not considered (by solving RLC equations). The results showed that, the negative (radially inward) Lorentz force was comparable with the case calculated by RLC solution, and it did not influence the final results significantly.
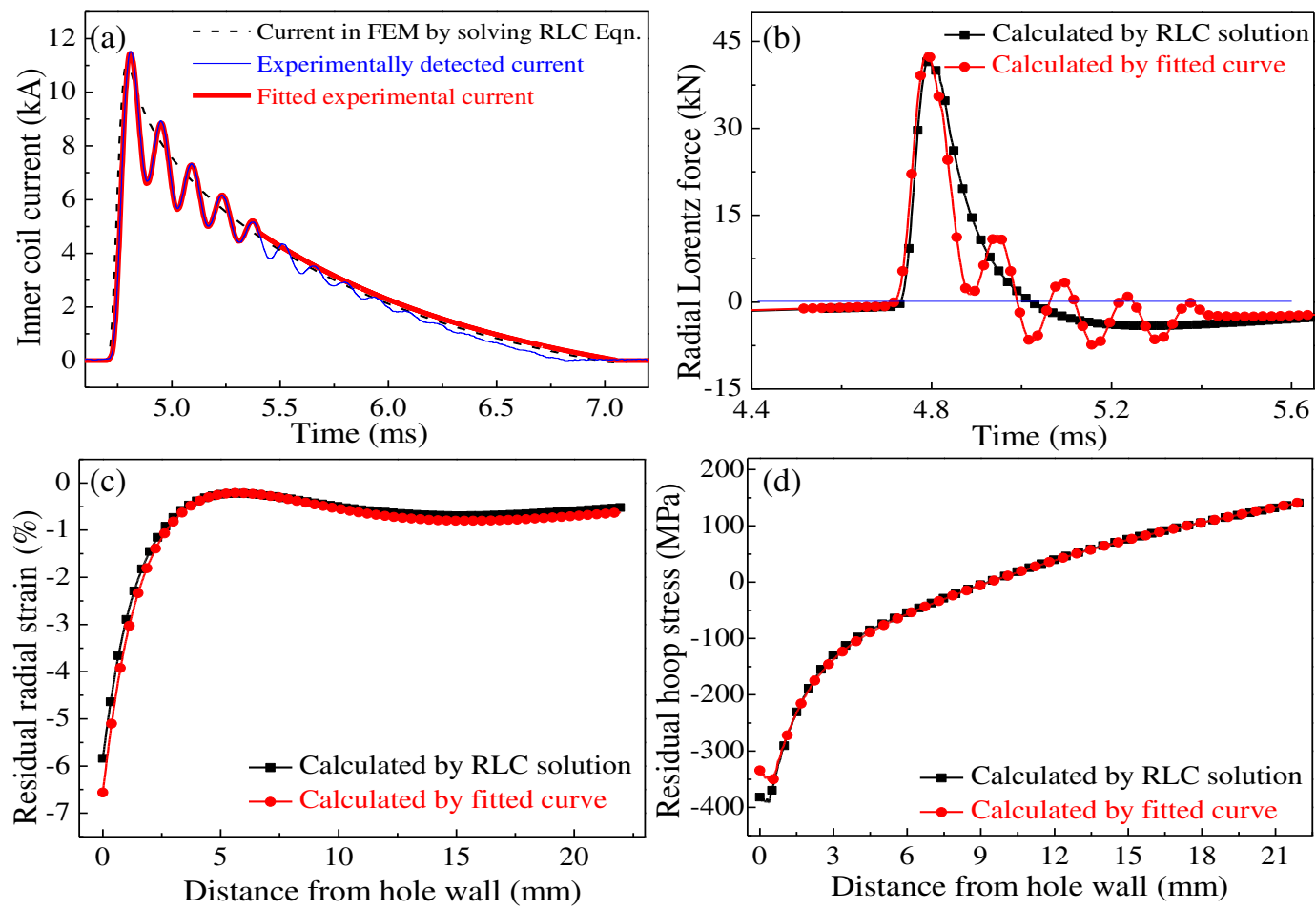
Fig. 23 Simulation results to study the influence of oscillation attenuation waveform: (a) the fitted oscillation attenuation waveform current, (b) the total Lorentz force, (c) the final residual radial strain and (d) the residual hoop stress

\section{Appendix B}

For simplicity, a single inner coil under pulsed currents were utilized, and the response of inductive reactance and the circuits resistance for were illustrated in Fig. 24.

The inductance of the coil could be given via

$$
Q_{m}=\frac{1}{2} I^{2} L
$$

in which $Q_{m}$ was the magnetic energy, $I$ was the coil current, $L$ was the inductance of the coil. And the inductive reactance could be obtained by,

$$
X_{L}=\frac{2 \pi}{T} L
$$

$X_{L}$ was the inductive reactance, $T$ was the period of the discharge current, and usually four times of the rising time of the pulsed current was used.
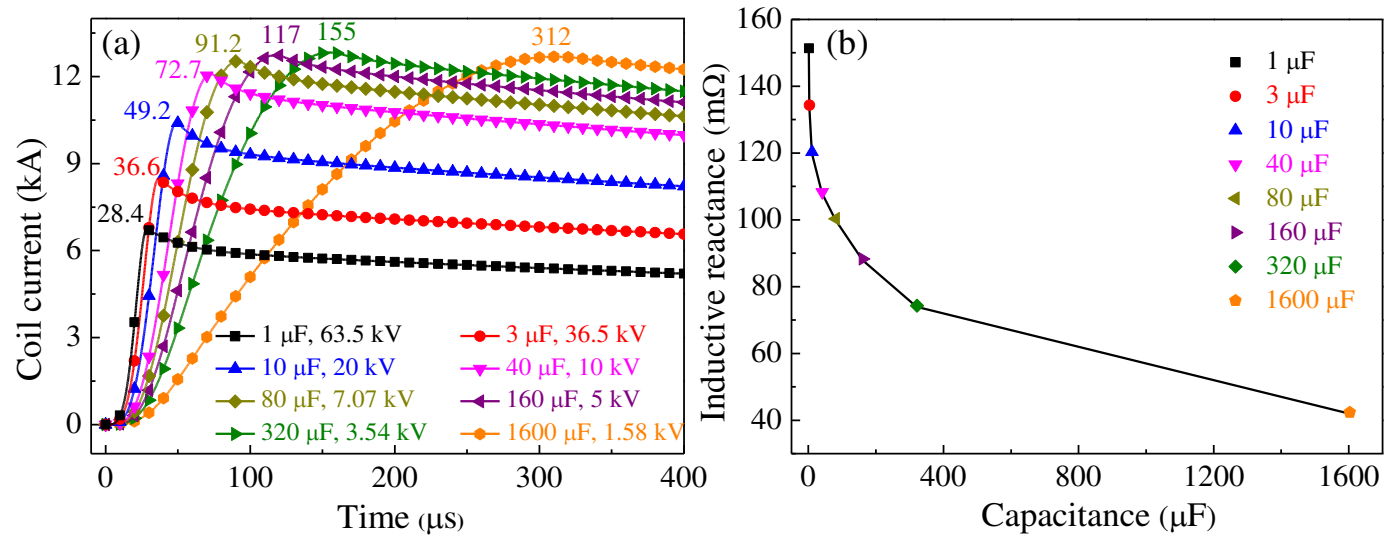

Fig. 24 Simulation results of the inductance of a single coil at high frequency for a constant energy

(2 kJ): (a) Coil current, (b) inductive reactance 
Authors' contributions Xiaofei $\mathrm{Xu}$ : experiment conceiving and designing, finite element simulation, original draft writing, funding acquisition. Huihui Geng: electromagnetic experiment conducting, experimental data analyzing. Qingshan Cao: fatigue test performing, strain measurement conducting. Quanliang Cao: supervision, conceptualization, methodology, funding acquisition, reviewing and editing. Liang Li: supervision, conceptualization, methodology, reviewing and editing. Xiaoping Ouyang: supervision, methodology, reviewing and editing. All authors have read and agreed to the published version of the manuscript.

Funding This work was supported by the Graduate Research and Innovation Project of Xiangtan University, China (XDCX2019B074), and the National Natural Science Foundation of China (51821005).

Availability of data and materials All data generated or analyzed during this study are included in the present article.

\section{Declarations}

Ethical approval Not applicable.

Consent to participate Not applicable.

Consent to publish Not applicable.

Competing interests The authors declare no competing interests.

\section{References}

[1] Xue F, Li F, Cui X (2019) Damage and fatigue analysis of AA7050-T7451 plate with cold expanded hole based on a micro-void evolution model. J Strain Anal Eng 54:105-115. https://doi.org/10.1177/0309324719833550.

[2] Liu H, Hu D, Wang R, Wang X, Jin S, Gu Y (2020) Experimental and numerical 
investigations on the influence of cold expansion on low cycle fatigue life of bolt holes in aeroengine superalloy disk at elevated temperature. Int $\mathrm{J}$ Fatigue 132:105390. https://doi.org/10.1016/j.ijfatigue.2019.105390.

[3] Faghih S, Shaha SK, Behravesh SB, Jahed H (2020) Split sleeve cold expansion of AZ31B sheet: Microstructure, texture and residual stress. Mater Des 186:108213. https://doi.org/10.1016/j.matdes.2019.108213.

[4] Stephen GJ, Pasang T, Withy BP (2013) The effect of pitting corrosion on split sleeve cold hole expanded, bare 7075-T651 aluminium alloy. J Manuf Process 15:115-120. https://doi.org/10.1016/j.jmapro.2012.09.008.

[5] Wang Y, Fu B, Nie L, Sun T (2019) Fatigue nucleation site of cold expansion hole varying as fatigue load level varies. SN Applied Sciences 1:867. https://doi.org/10.1007/s42452-019-0880-y.

[6] Kumar BM, Panaskar NJ, Sharma A (2014) A fundamental investigation on rotating tool cold expansion: numerical and experimental perspectives. Int $\mathrm{J} A d v$ Manuf Tech 73:1189-1200. https://doi.org/10.1007/s00170-014-5888-2.

[7] Soyama H, Takeo F (2016) Comparison between cavitation peening and shot peening for extending the fatigue life of a duralumin plate with a hole. J Mater Process Technol 227:80-87. https://doi.org/10.1016/j.jmatprotec.2015.08.012.

[8] Amjad K, Wang W-C, Patterson E (2016) A comparison of split sleeve cold expansion in thick and thin plates. J Strain Anal Eng 51:375-386. https://doi.org/10.1177/0309324716642621.

[9] Ofsthun M (2003) When fatigue quality enhancers do not enhance fatigue quality. 
Int J Fatigue 25:1223-1228. https://doi.org/10.1016/S0142-1123(03)00122-1.

[10] Poolsuk S, Sharpe WNJ (1978) Measurement of the elastic-plastic boundary around coldworked fastener holes. J Appl Mech 45:515-520. https://doi.org/10.1115/1.3424354.

[11] Sanford RJ, Link RE (1989) Holographic measurement of the elastic-plastic boundary surrounding cold-expanded holes. J Strain Anal Eng 24:103-106. https://doi.org/10.1243/03093247V242103.

[12] Hou S, Zhu Y, Cai Z, Wang Y, Ni Y, Du X (2019) Effect of hole cold expansion on fatigue performance of corroded 7B04-T6 aluminium alloy. Int J Fatigue 126:210220. https://doi.org/10.1016/j.ijfatigue.2019.05.008.

[13] Bahloul A, Mhalla MM, Bouraoui C (2018) Crack repair of SENT specimen using the interference fit process. J Alloys Compd 748:363-374. https://doi.org/10.1016/j.jallcom.2018.03.142.

[14] Özdemir AT, Hermann R (1999) Effect of expansion technique and plate thickness on near-hole residual stresses and fatigue life of cold expanded holes. J Mater Sci 37:1243-1252. https://doi.org/10.1023/A:1004521309415.

[15] Zhou Z, Fu J, Cao Q, Lai Z, Xiong Q, Han X, et al. (2017) Electromagnetic coldexpansion process for circular holes in aluminum alloy sheets. J Mater Process Technol 248:49-55. https://doi.org/10.1016/j.jmatprotec.2017.04.024.

[16] Ouyang S, Li X, Li C, Du L, Peng T, Han X, et al. (2020) Investigation of the electromagnetic attractive forming utilizing a dual-coil system for tube bulging. $\mathrm{J}$ Manuf Process 49:102-115. https://doi.org/10.1016/j.jmapro.2019.11.006. 
[17] Xiong Q, Huang H, Xia L, Tang H, Qiu L (2019) A research based on advance dual-coil electromagnetic forming method on flanging of small-size tubes. Int $\mathbf{J}$ Adv Manuf Tech 102:4087-4094. https://doi.org/10.1007/s00170-019-03498-4.

[18] Cao Q, Li Z, Lai Z, Li Z, Han X, Li L (2019) Analysis of the effect of an electrically conductive die on electromagnetic sheet metal forming process using the finite element-circuit coupled method. Int J Adv Manuf Tech 101:549-563. https://doi.org/10.1007/s00170-018-2798-8.

[19] Geng H, Sun L, Li G, Cui J, Huang L, Xu Z (2019) Fatigue fracture properties of magnetic pulse welded dissimilar Al-Fe lap joints. Int J Fatigue 121:146-154. https://doi.org/10.1016/j.ijfatigue.2018.12.027.

[20] Yu H, Tong Y (2017) Magnetic pulse welding of aluminum to steel using uniform pressure electromagnetic actuator. Int J Adv Manuf Tech 91:2257-2265. https://doi.org/10.1007/s00170-016-9928-y.

[21] Yu H, Li C (2009) Effects of current frequency on electromagnetic tube compression. J Mater Process Technol 209:1053-1059. https://doi.org/10.1016/j.jmatprotec.2008.03.011.

[22] Cao Q, Du L, Li Z, Lai Z, Li Z, Chen M, et al. (2019) Investigation of the Lorentzforce-driven sheet metal stamping process for cylindrical cup forming. J Mater Process Technol 271:532-541. https://doi.org/10.1016/j.jmatprotec.2019.03.002.

[23] Ouyang S, Li C, Du L, Li X, Lai Z, Peng T, et al. (2021) Electromagnetic forming of aluminum alloy sheet metal utilizing a low-frequency discharge: A new method for attractive forming. J Mater Process Technol 291:117001. 
https://doi.org/10.1016/j.jmatprotec.2020.117001.

[24] Du L, Xia L, Li X, Qiu L, Lai Z, Chen Q, et al. (2021) Adjustable current waveform via altering the damping coefficient: A new way to reduce Joule heating in electromagnetic forming coils. J Mater Process Technol 293:117086. https://doi.org/10.1016/j.jmatprotec.2021.117086.

[25] Liu N, Lai Z, Cao Q, Han X, Huang Y, Li X, et al. (2019) Effects of air on metallic sheet deformation by electromagnetic forming. Int J Adv Manuf Tech 103:311324. https://doi.org/10.1007/s00170-019-03479-7.

[26] Kay G. Failure modeling of titanium-6Al-4V and 2024-T3 aluminum with the Johnson-Cook material model. Lawrence Livermore National Lab., CA (US), 2002. https://doi.org/10.2172/15006359.

[27] Cao Q, Han X, Lai Z, Xiong Q, Zhang X, Chen Q, et al. (2015) Analysis and reduction of coil temperature rise in electromagnetic forming. J Mater Process Technol 225:185-194. https://doi.org/10.1016/j.jmatprotec.2015.02.006. 


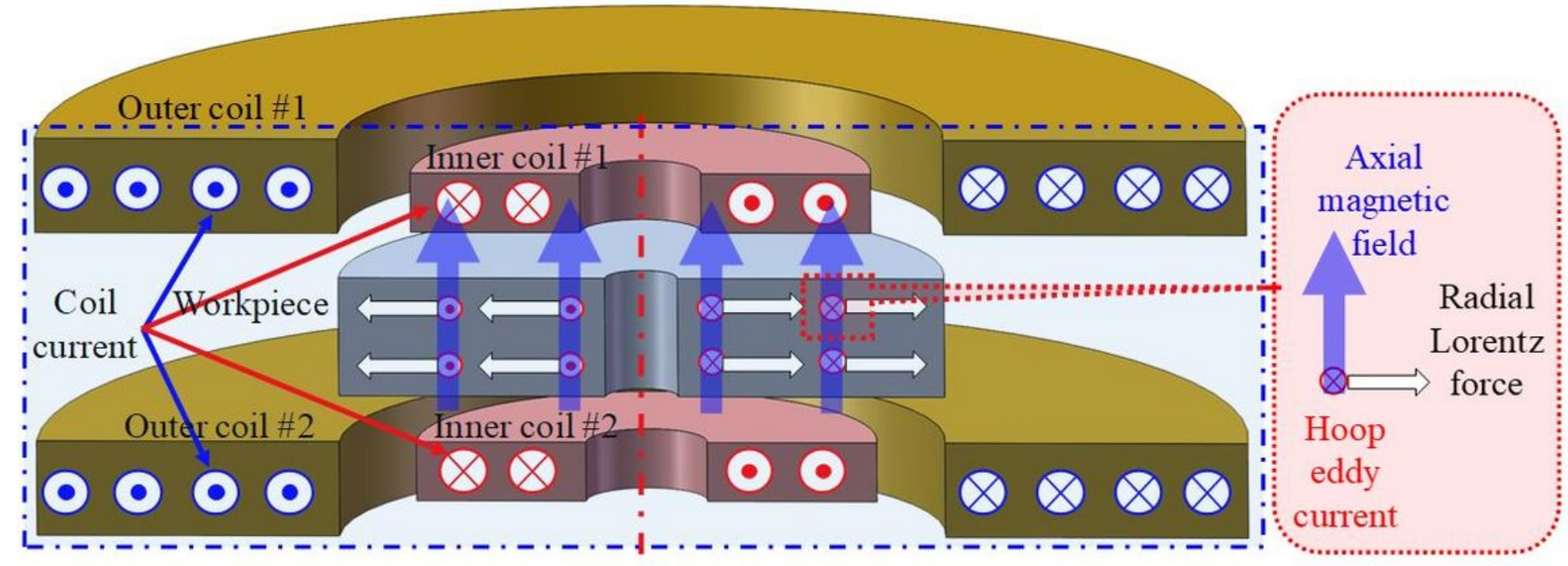

Figure 1

Schematic of electromagnetic cold expansion system

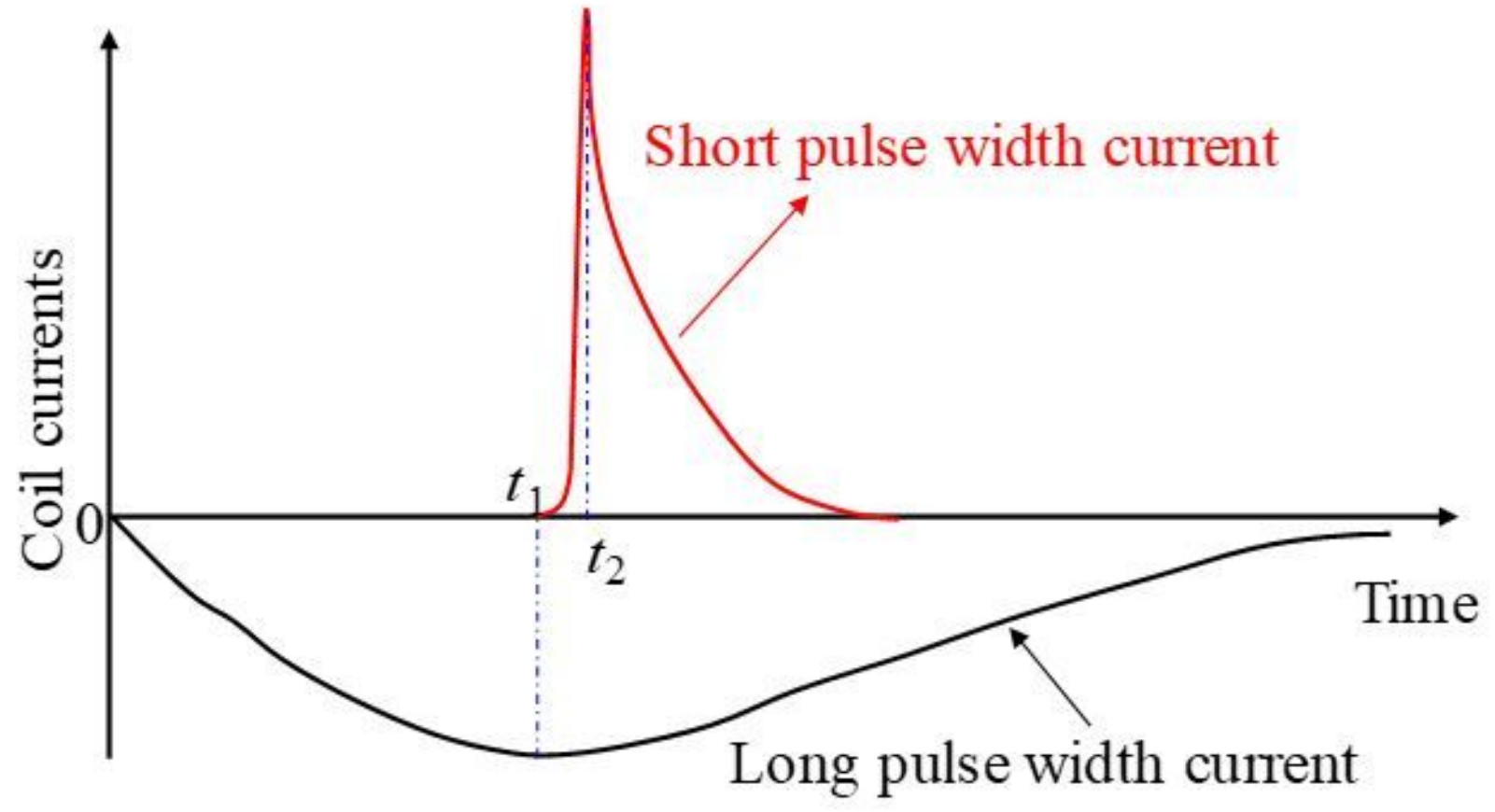

Figure 2

Schematic of the coil currents 


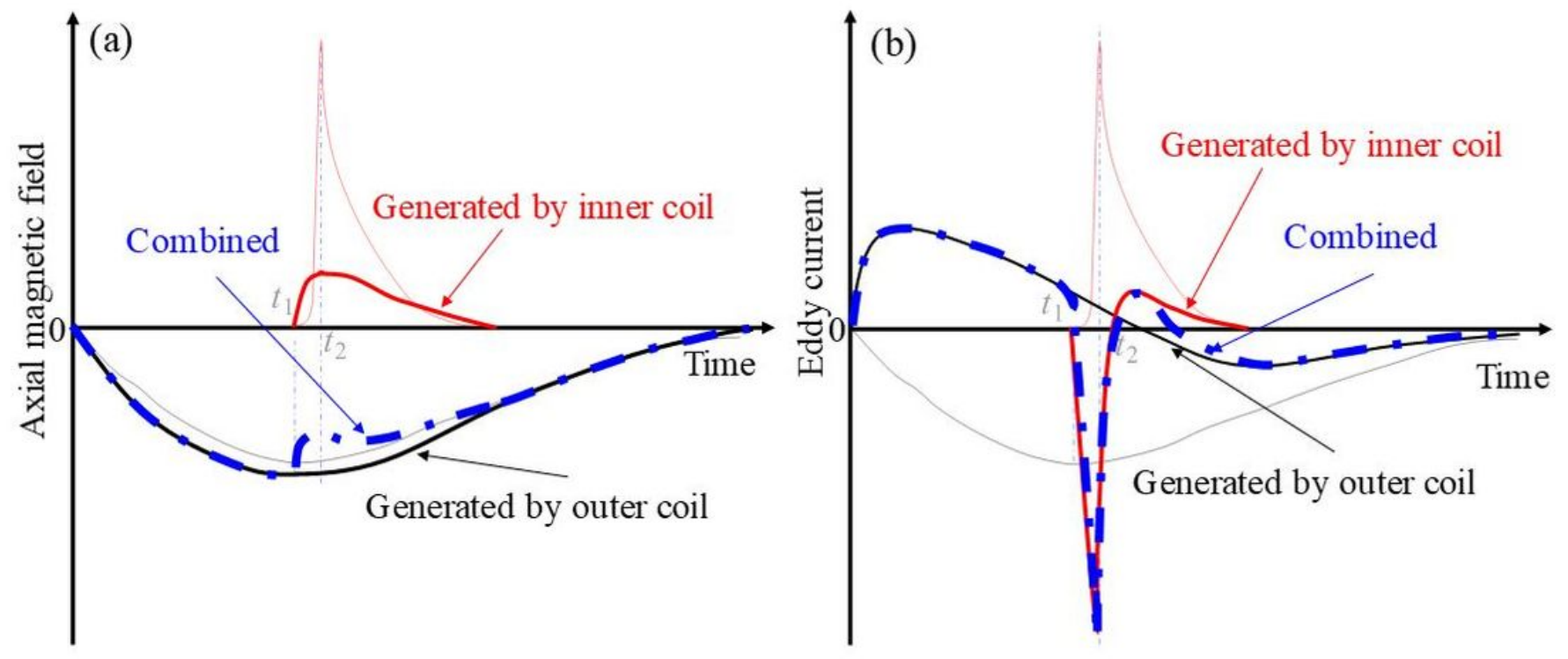

Figure 3

Schematic diagram of the expected (a) axial magnetic field and (b) eddy current, the background transparent lines show the discharge current

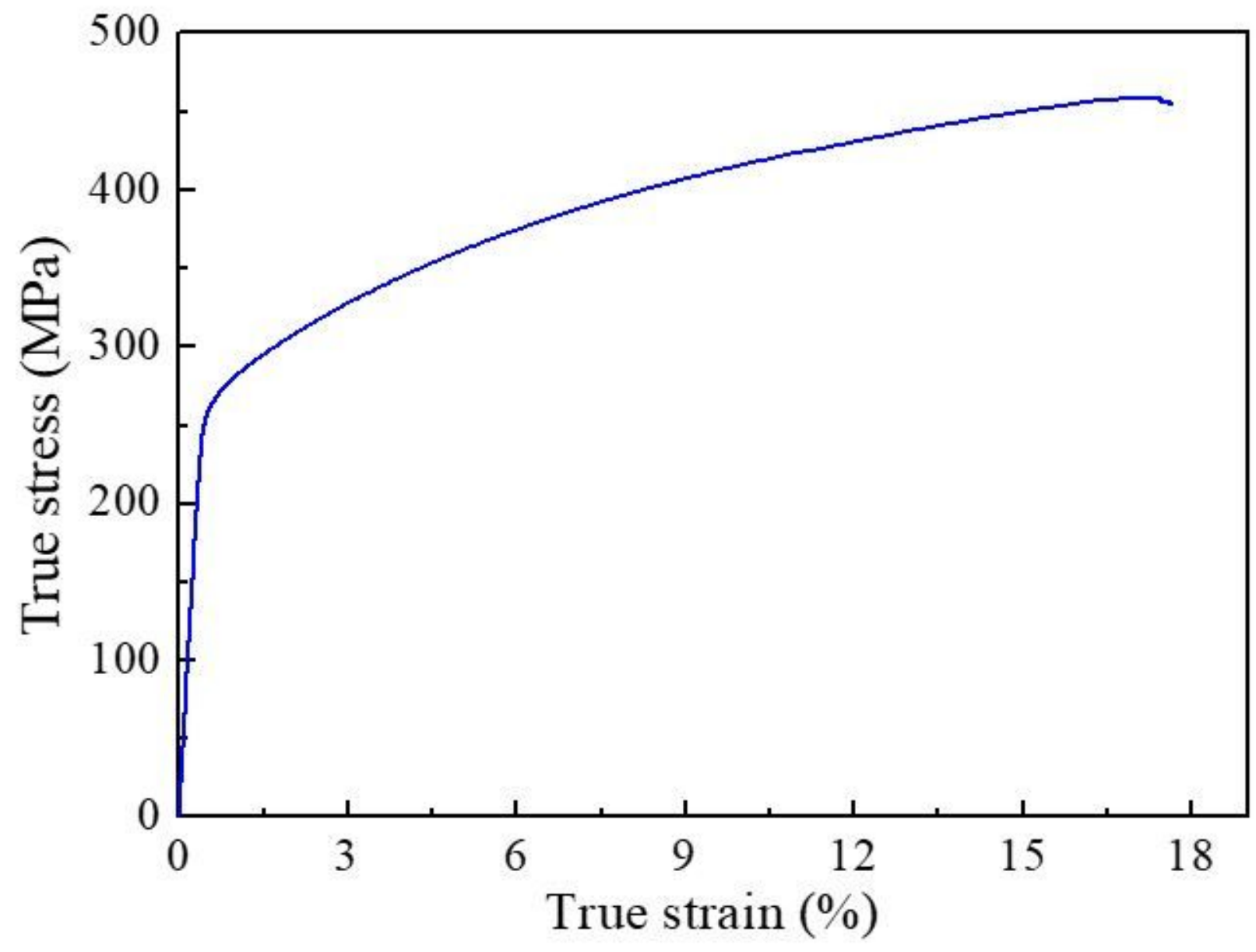


Figure 4

The tested stress-strain curve of the material (2A12-T4)

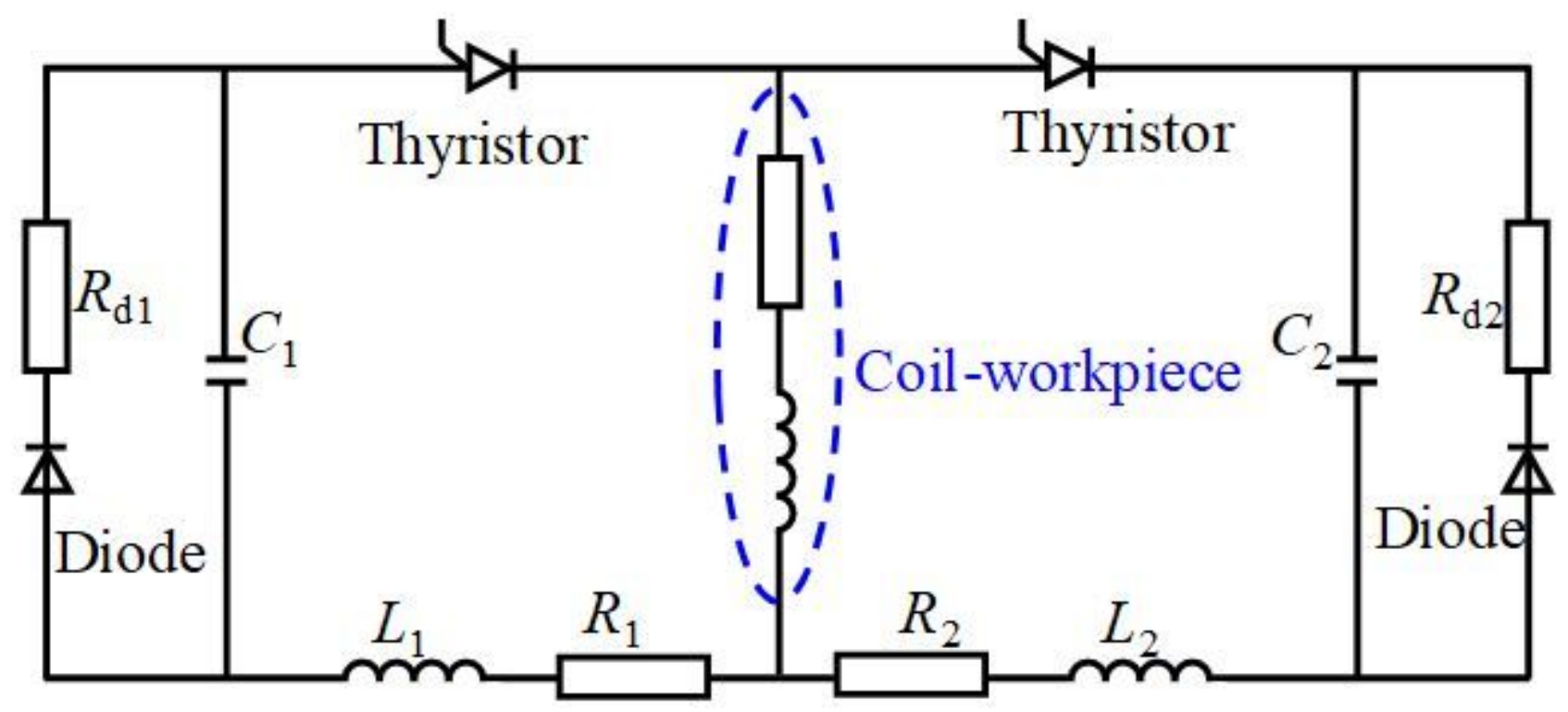

Figure 5

Schematic diagram of the electrical circuit of the EMCE system
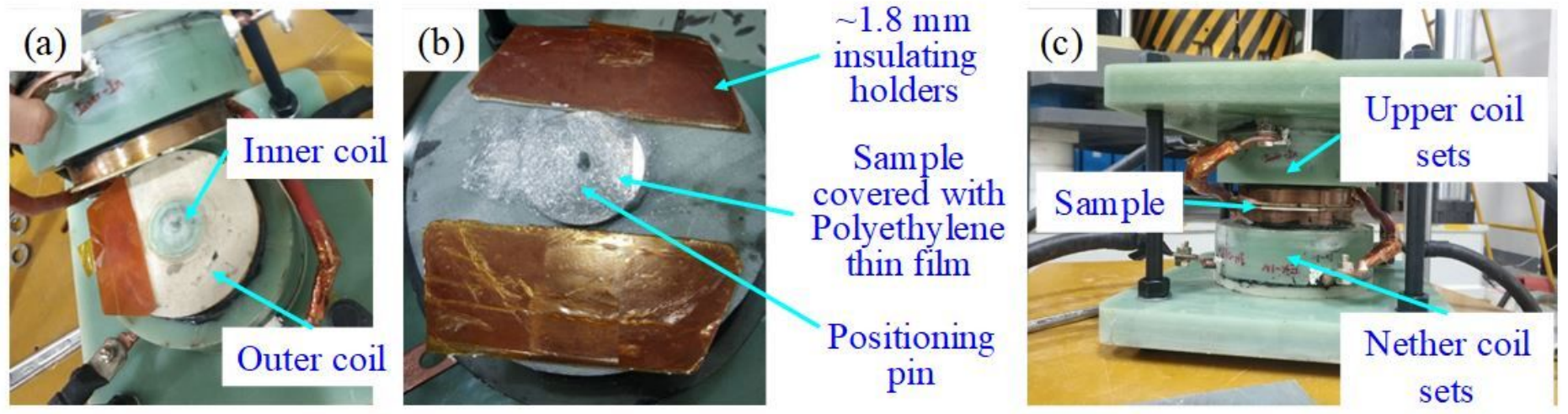

Figure 6

The assembling of the EMCE system: (a) the coil sets, (b) the holders and Polyethylene thin film used and (c) the coil sets and specimen 

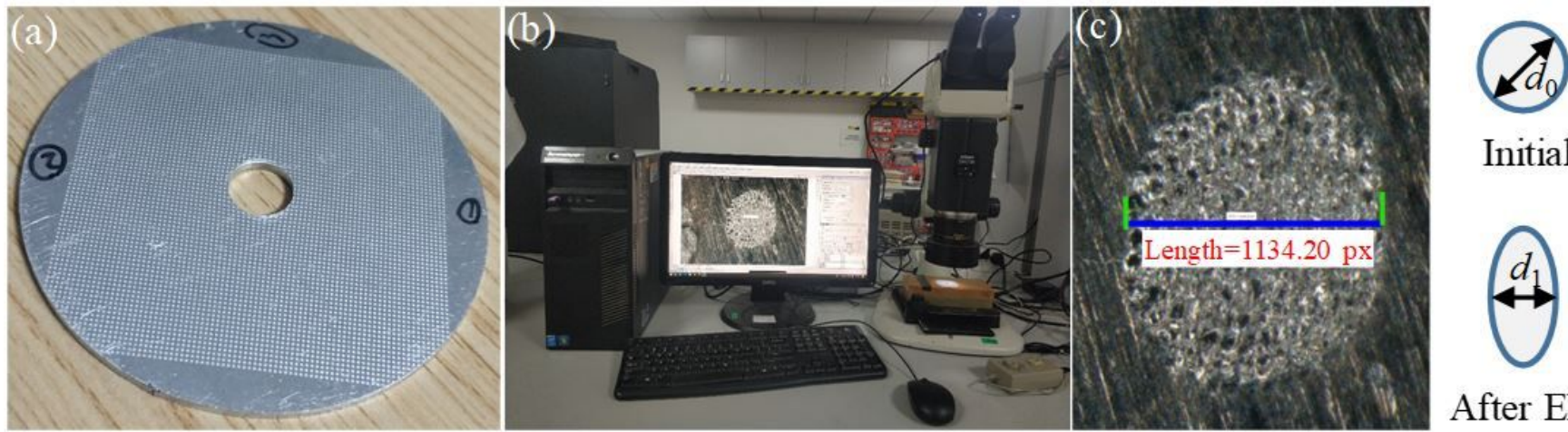

After EMCE

\section{Figure 7}

Deformation measurement of the EMCE specimen: (a) the microgrids etched on the specimen, (b) the test platform and (c) the deformed grid

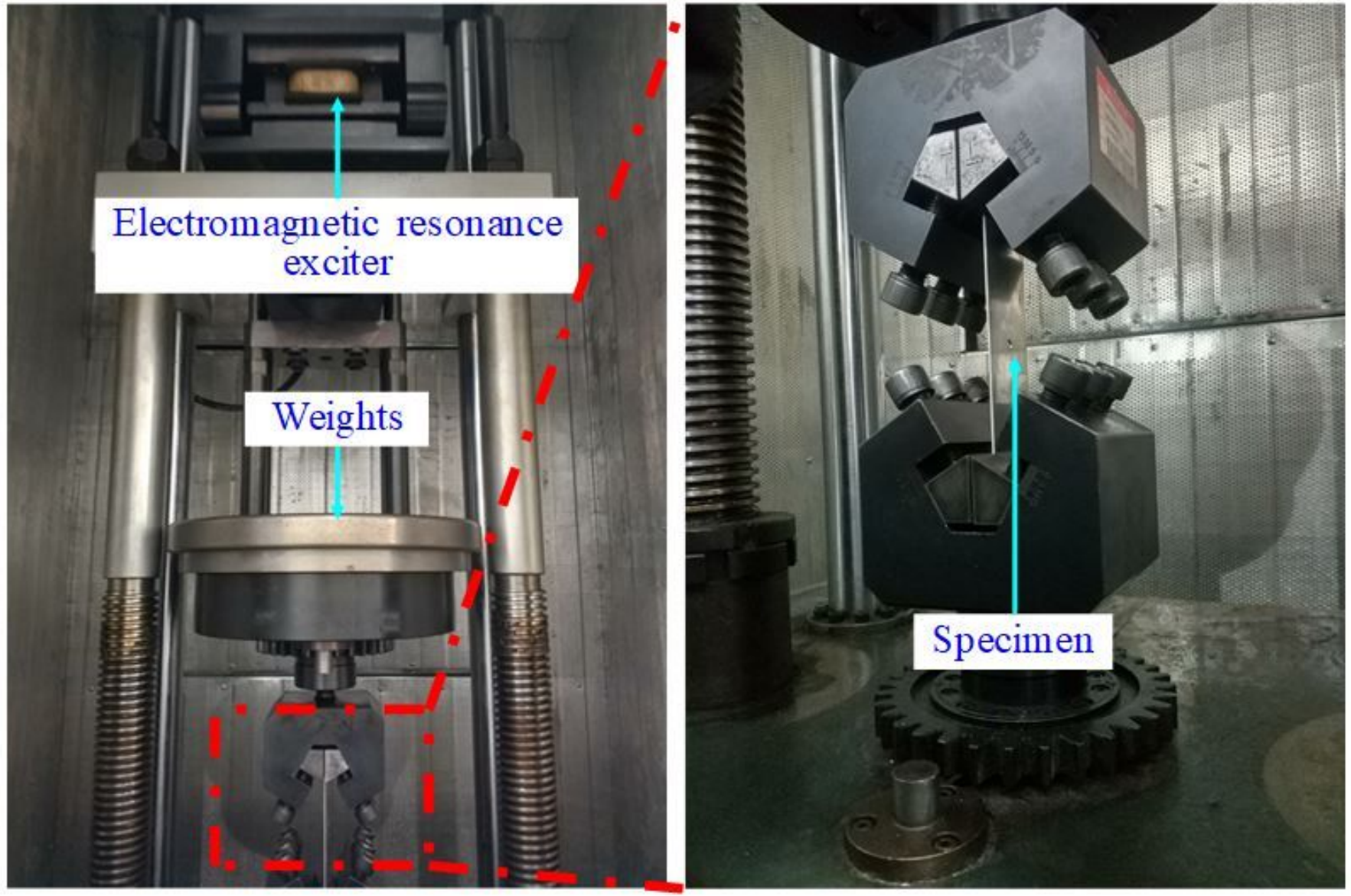

\section{Figure 8}

High frequency fatigue life test platform 


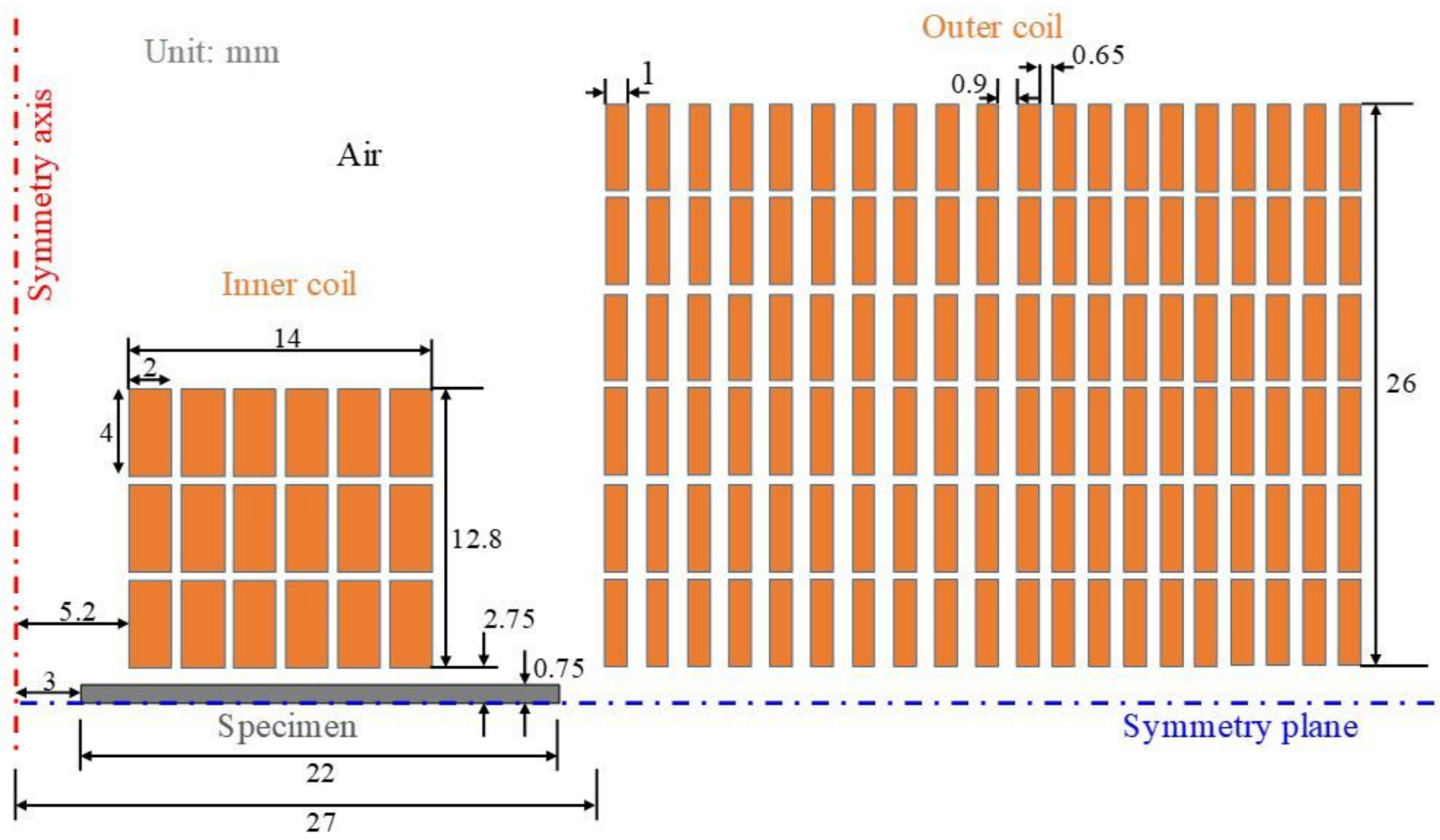

Figure 9

Detailed geometric parameters of the EMCE coils and specimen from a quarter section view 


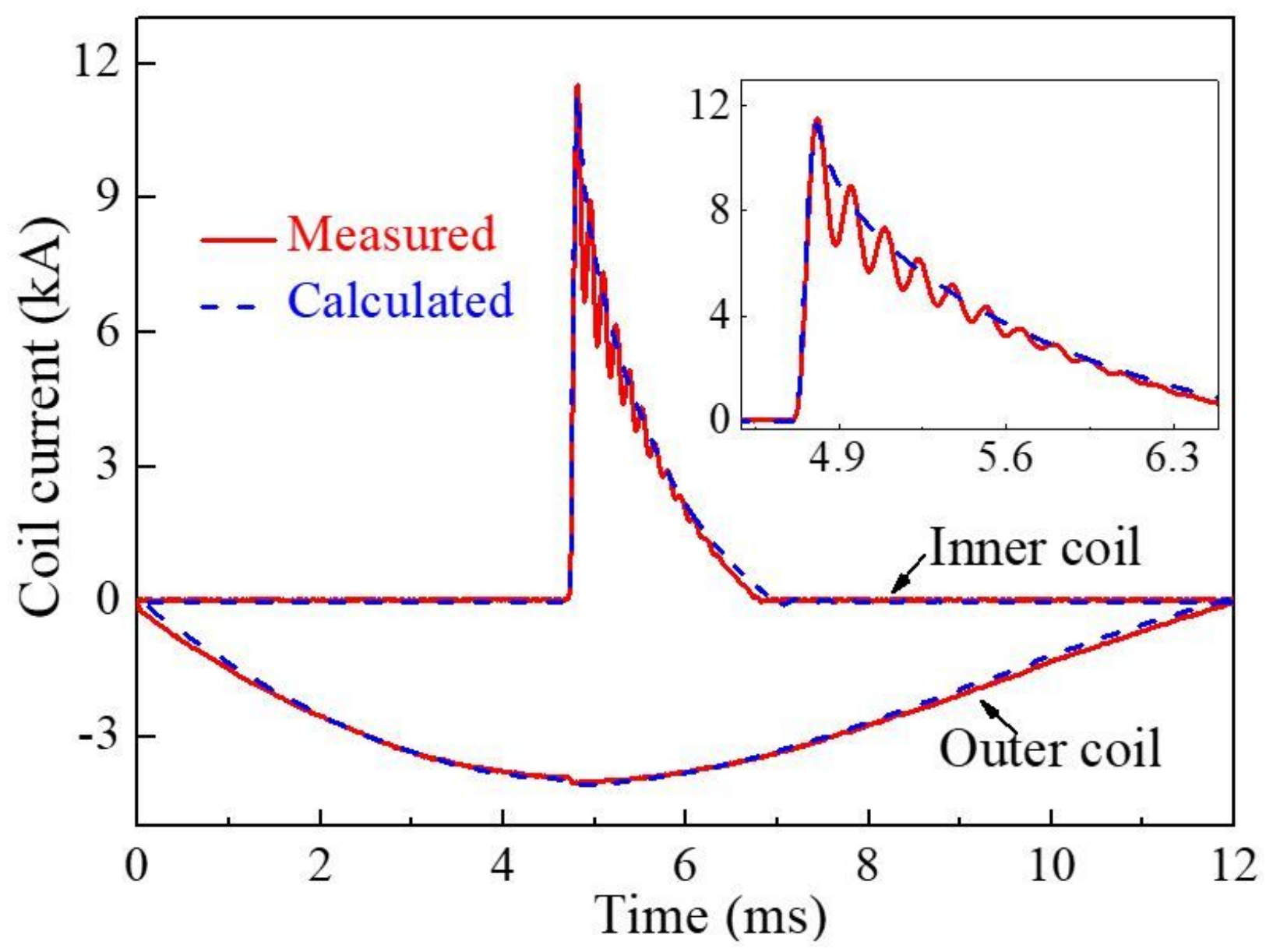

Figure 10

The coil currents comparison between the FEM simulation and the experiment when U1=4 kV, U2=6 kV
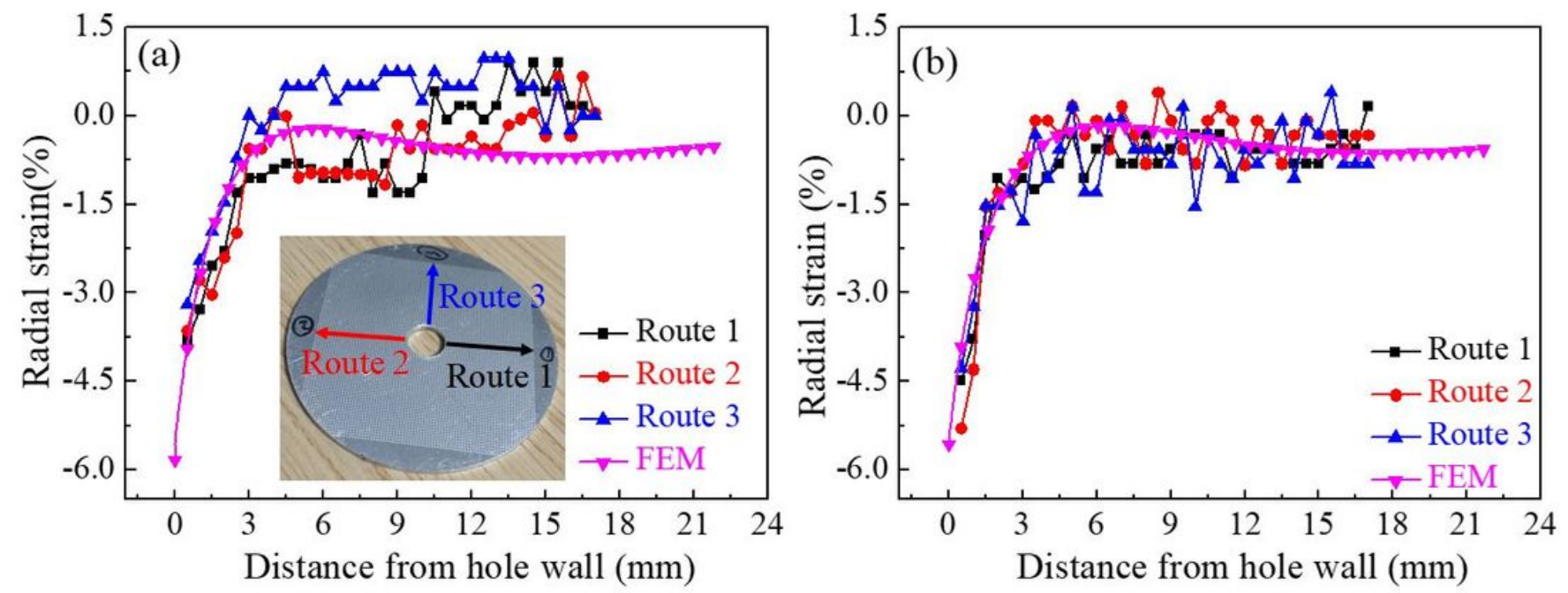

Figure 11 
The residual radial strains under different discharge voltages: (a) U1=4 kV, U2=6 kV, (b) U1=4.5 kV, U2=5 $\mathrm{kV}$
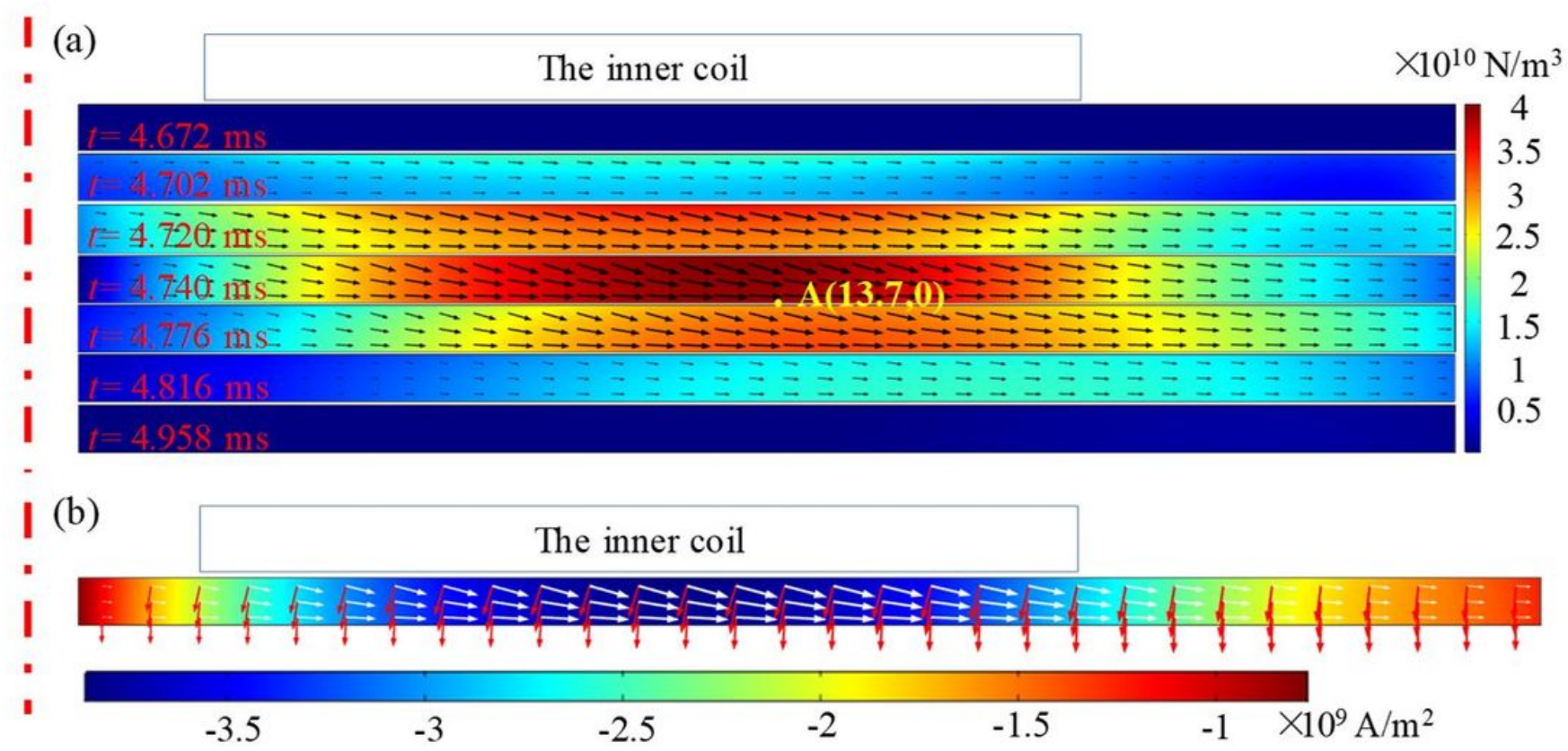

\section{Figure 12}

(a) Distribution of the radial Lorentz force component and Lorentz force vectors inside the plate during the EMCE process. (b) Distribution of the eddy current density (color), magnetic field vectors (red arrows) and Lorentz force density vectors (white arrows) at $\mathrm{t}=4.740 \mathrm{~ms}$
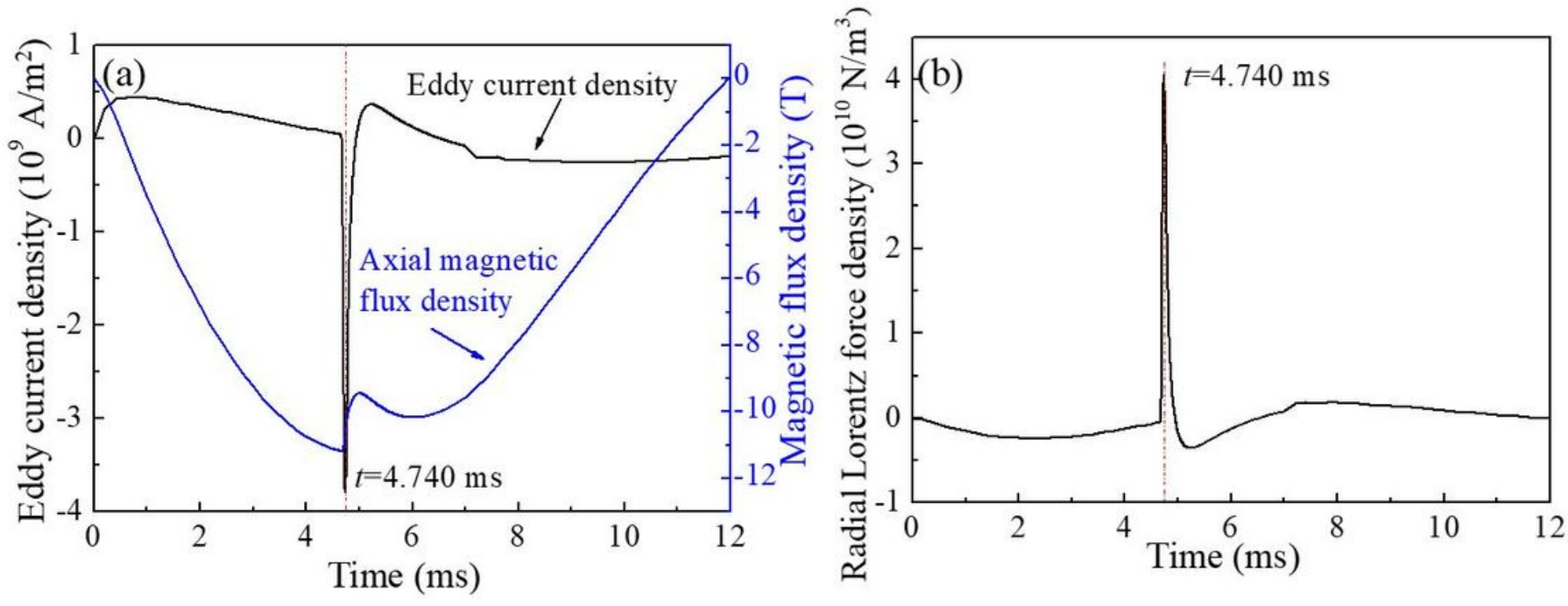

\section{Figure 13}

(a) The eddy current density and axial magnetic flux density and (b) radial Lorentz force density at point A 

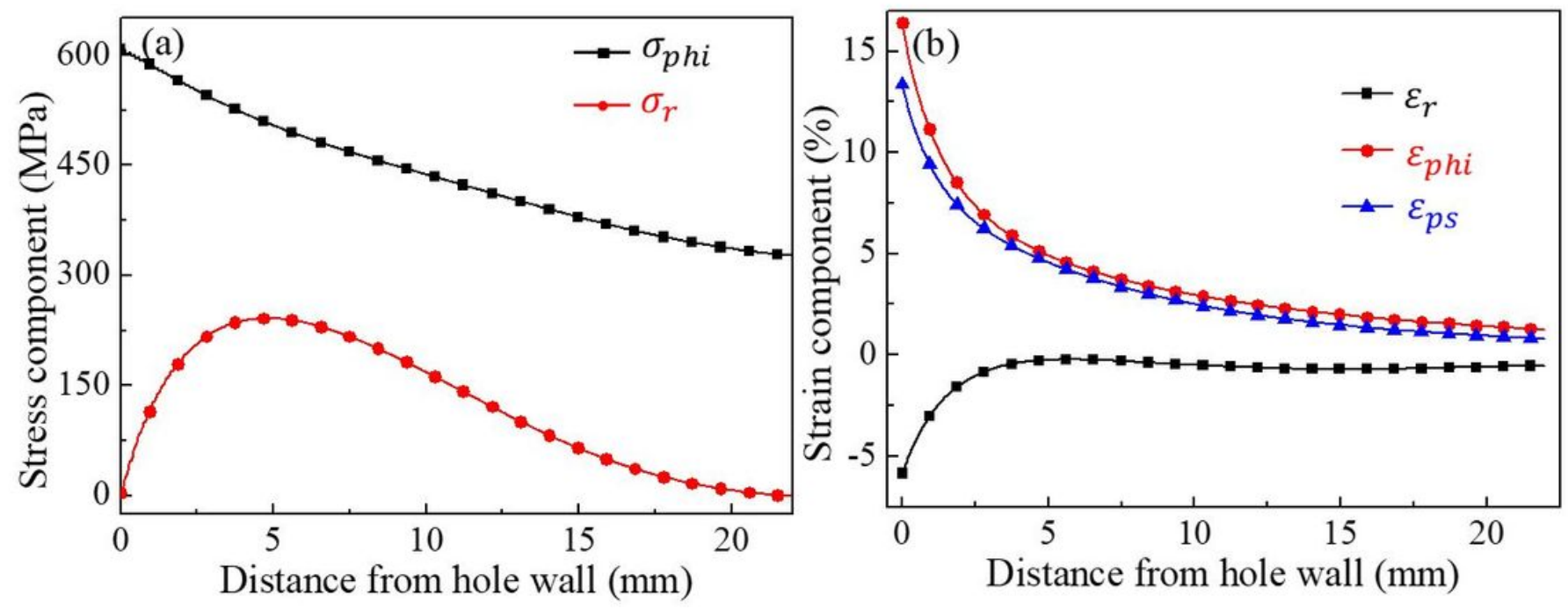

Figure 14

(a) Stress components at $\mathrm{z}=0 \mathrm{~mm}$ at $\mathrm{t}=4.740 \mathrm{~ms}$. (b) The residual hoop strain after the EMCE process at $\mathrm{z}=0 \mathrm{~mm}$ ( $\varepsilon p s$ is the effective plastic strain)
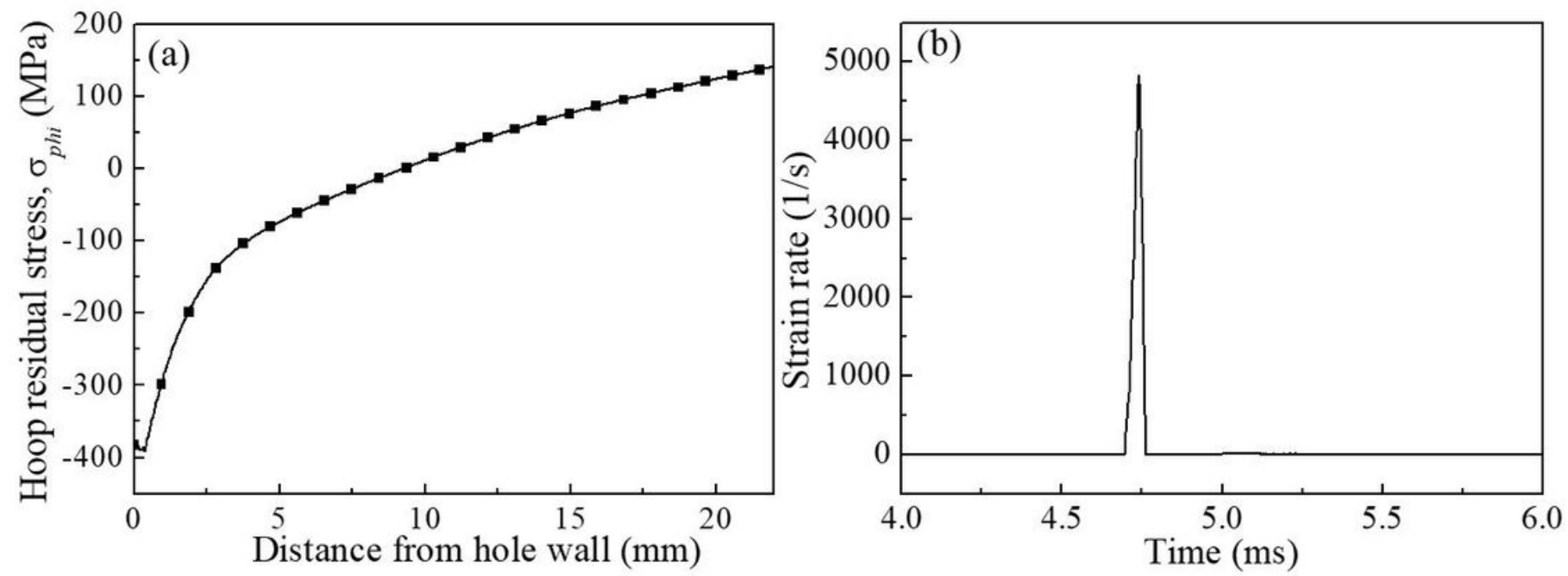

Figure 15

(a) The residual hoop stress after the EMCE process at $z=0 \mathrm{~mm}$. (b) Huge strain rate during the EMCE process at the hole wall 

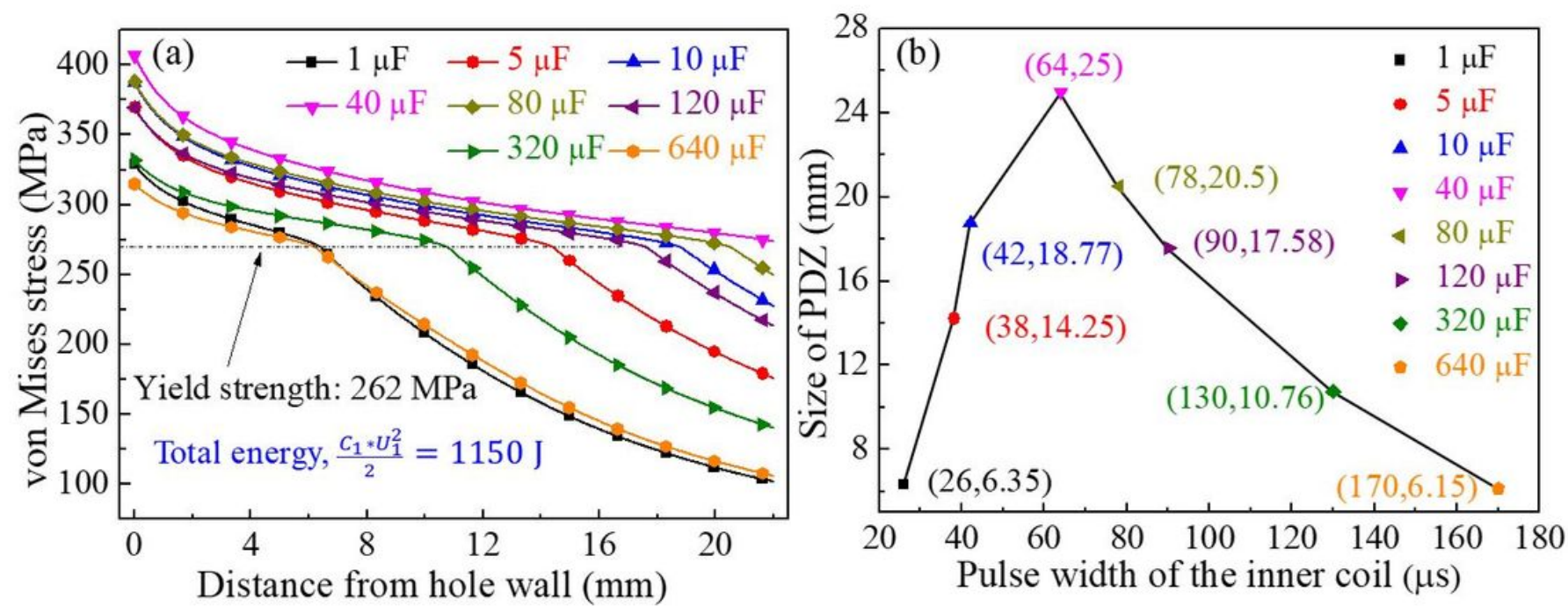

Figure 16

(a) The maximum von Mises stress distribution at $z=0 \mathrm{~mm}$. (b) The relationship between short pulse width and the size of the PDZ
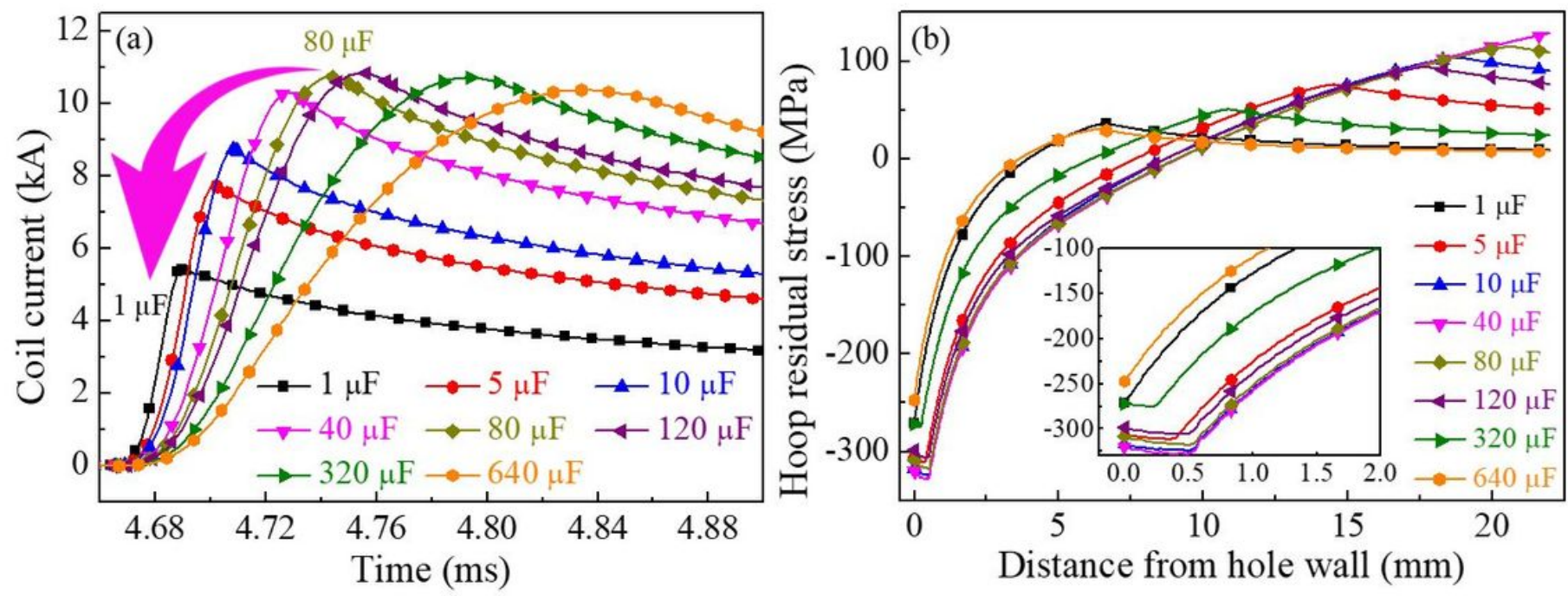

Figure 17

Simulated results under different discharge conditions: (a) the inner coil current, and (b) the hoop residual stress at $\mathrm{z}=0 \mathrm{~mm}$ 


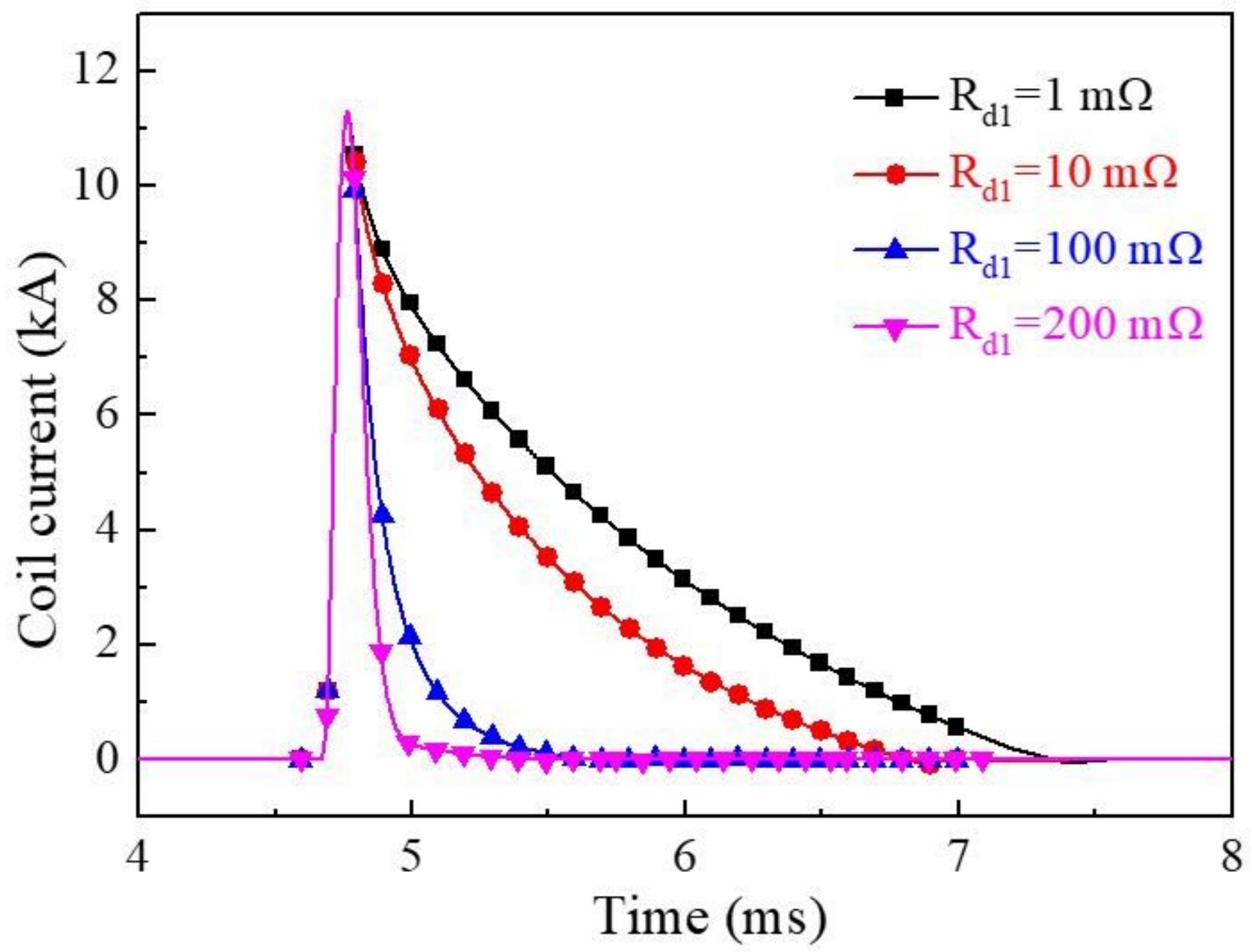

Figure 18

The inner coil current with varied crowbar resistance
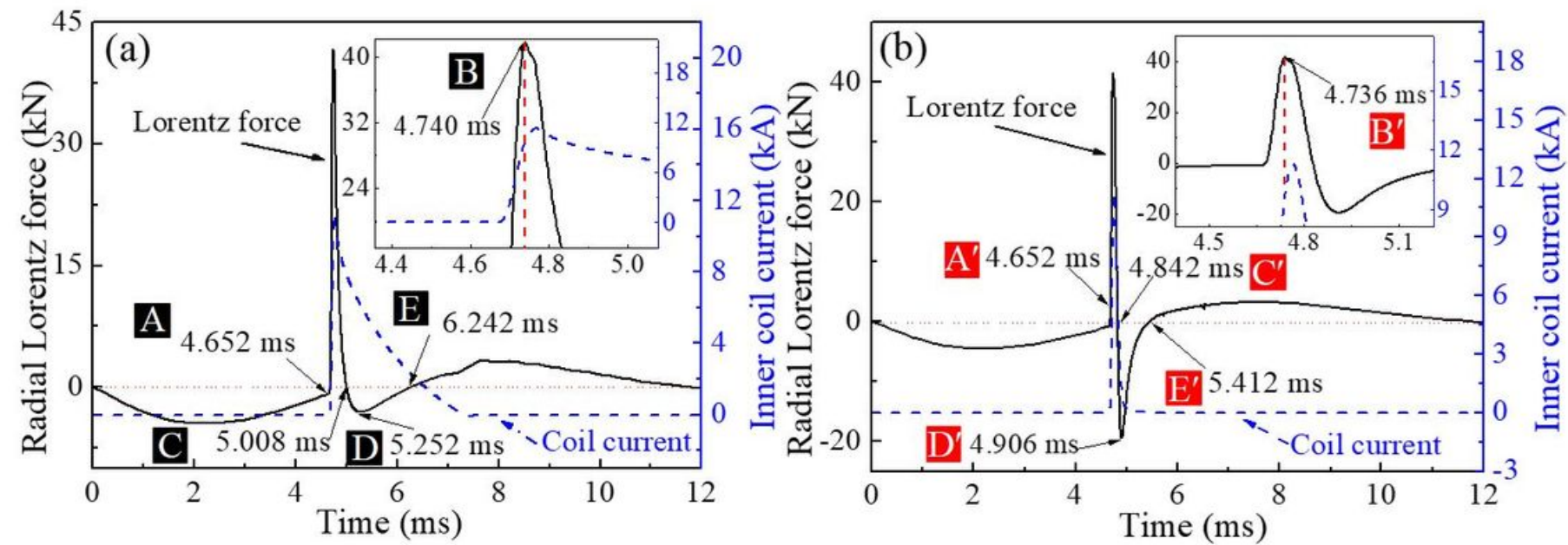

Figure 19 
The radial Lorentz force at the five specific time points during the EMCE process when (a) Rd1=1 $\mathrm{m} \Omega$, (b) $\mathrm{Rd} 1=200 \mathrm{~m} \Omega$

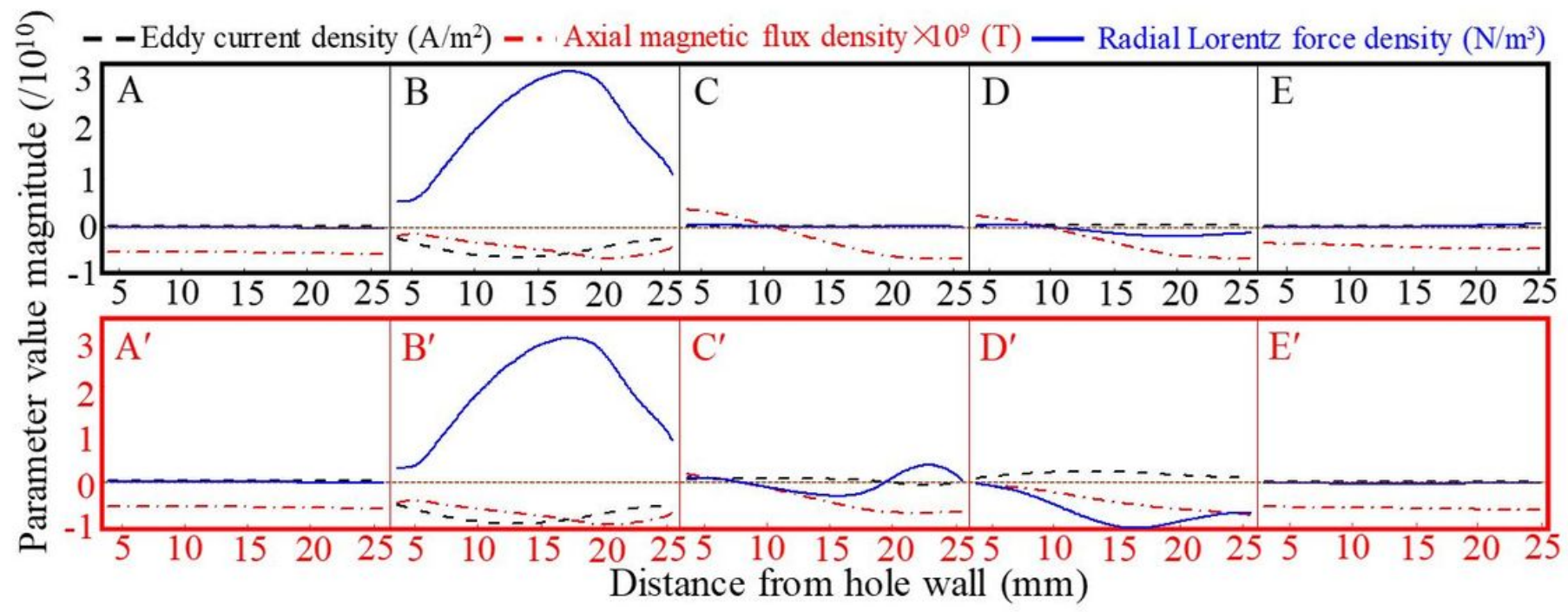

Figure 20

The eddy current, axial magnetic flux density and radial Lorentz force density during the EMCE process when $\mathrm{Rd} 1=1 \mathrm{~m} \Omega$ (top row) and $200 \mathrm{~m} \Omega$ (bottom row), at $\mathrm{z}=0$. To make the values of axial magnetic flux density comparable, its value was expanded by 109 times 


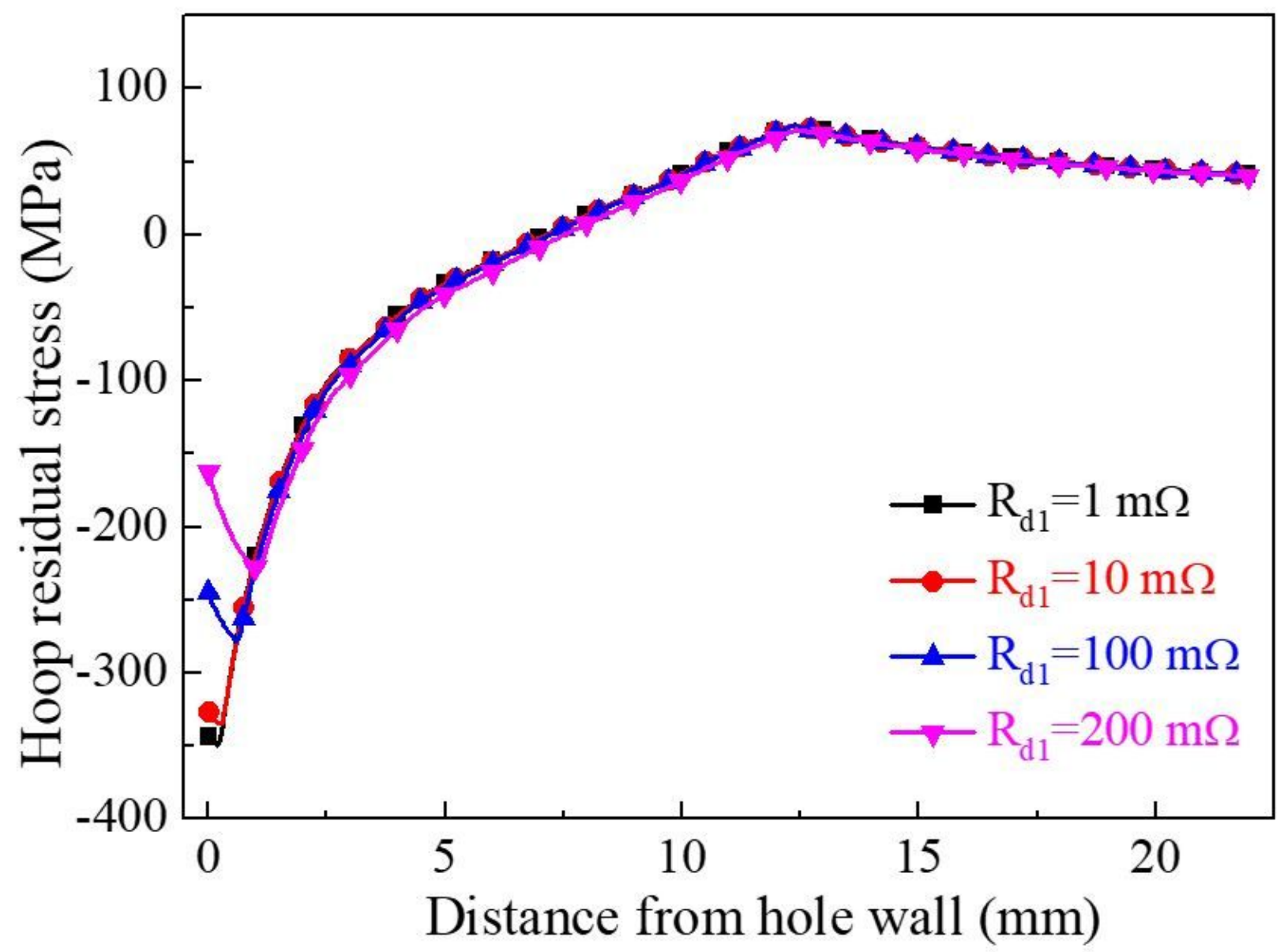

Figure 21

The hoop residual stress under different crowbar resistance of the inner-coil circuit at $z=0 \mathrm{~mm}$ 


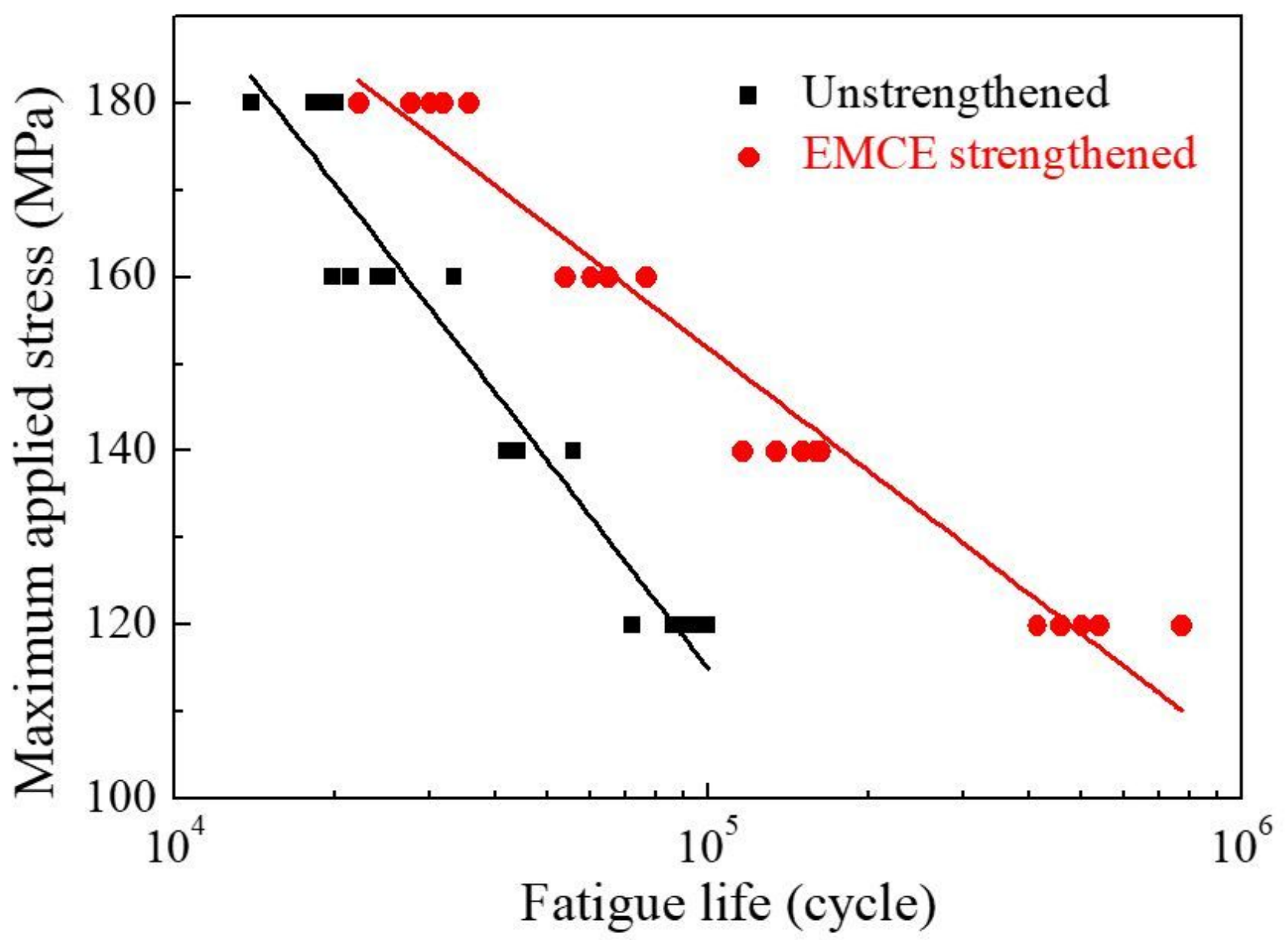

Figure 22

The S-N curve comparison of the specimens for unstrengthened and EMCE strengthened 

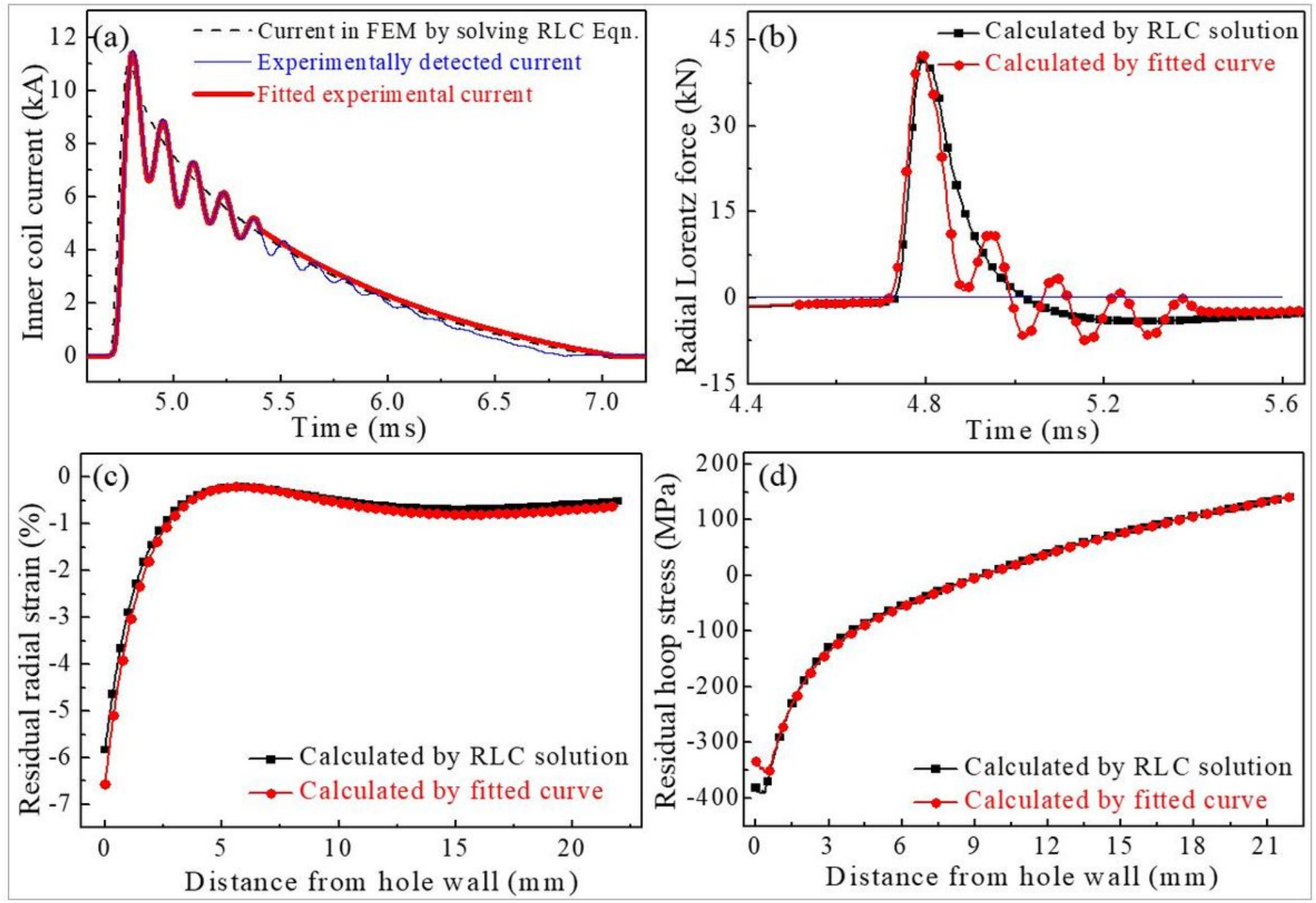

\section{Figure 23}

Simulation results to study the influence of oscillation attenuation waveform: (a) the fitted oscillation attenuation waveform current, (b) the total Lorentz force, (c) the final residual radial strain and (d) the residual hoop stress
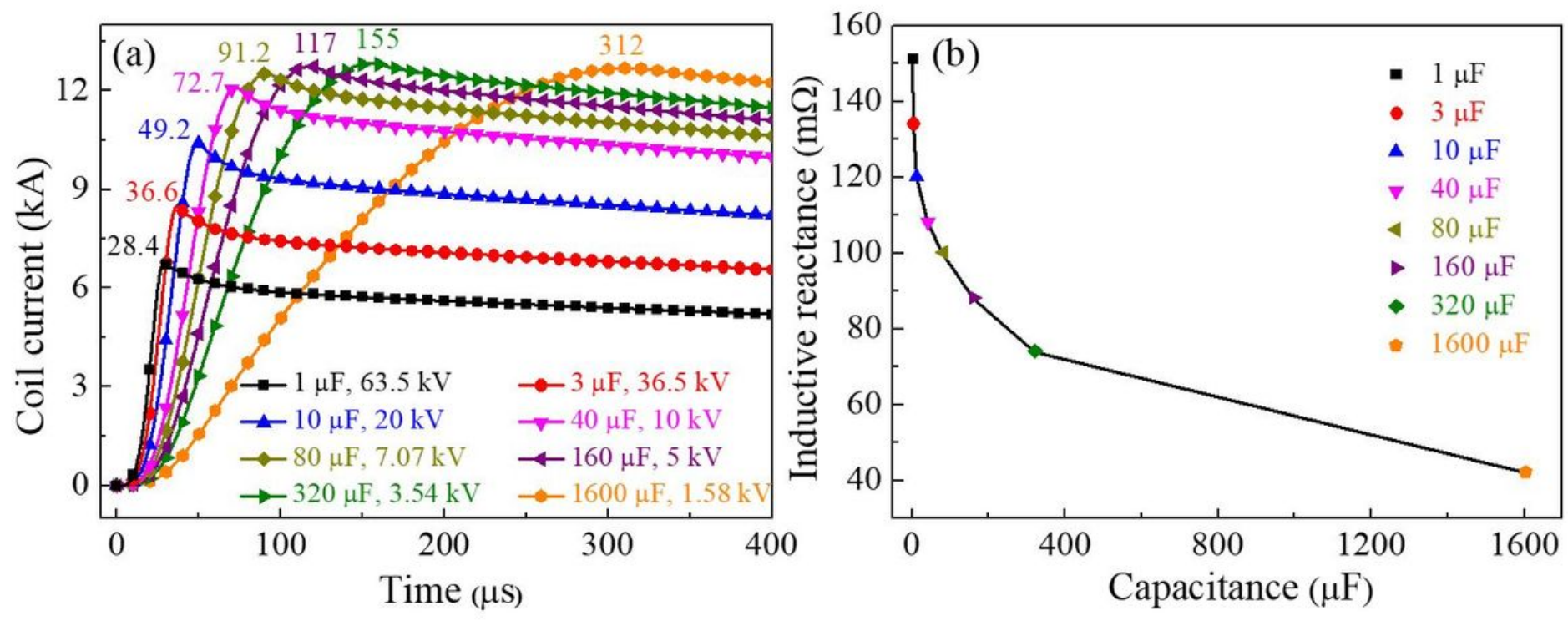
Figure 24

Simulation results of the inductance of a single coil at high frequency for a constant energy $(2 \mathrm{~kJ})$ : (a) Coil current, (b) inductive reactance 